Article

\title{
The Potential of Reflectance and Laser Induced Luminescence Spectroscopy for Near-Field Rare Earth Element Detection in Mineral Exploration
}

\author{
Sandra Lorenz ${ }^{1, *(\mathbb{C}, \text { Jan Beyer }}{ }^{2}$, Margret Fuchs ${ }^{1}$, Peter Seidel ${ }^{1}$, David Turner ${ }^{3}$, \\ Johannes Heitmann ${ }^{2}$ and Richard Gloaguen ${ }^{1}$ (I) \\ 1 Helmholtz-Zentrum Dresden-Rossendorf, Helmholtz Institute Freiberg for Resource Technology, \\ Division "Exploration Technology", Chemnitzer Str. 40, 09599 Freiberg, Germany; m.fuchs@hzdr.de (M.F.); \\ p.seidel@hzdr.de (P.S.); r.gloaguen@hzdr.de (R.G.) \\ 2 Institute of Applied Physics, Faculty of Chemistry and Physics, Technische Universität Bergakademie \\ Freiberg, Leipziger Straße 23, 09599 Freiberg, Germany; jan.beyer@physik.tu-freiberg.de (J.B.), \\ johannes.heitmann@physik.tu-freiberg.de (J.H.) \\ 3 Department of Earth, Ocean and Atmospheric Sciences, University of British Columbia, \\ Vancouver, BC V6T 1Z4, Canada; dturner@eoas.ubc.ca \\ * Correspondence: s.lorenz@hzdr.de; Tel.: +49-351-260-4487
}

Received: 28 November 2018; Accepted: 22 December 2018; Published: 23 December 2018

\begin{abstract}
New energy, transport, computer and telecommunication technologies require an increasing supply of rare earth elements (REEs). As a consequence, adequate and robust detection methods become essential for the exploration and discovery of new deposits, the improved characterization of existing deposits and the future recycling of today's high-tech products. Within this paper, we investigate the potential of combining passive reflectance (imaging and point sampling) with laser stimulated luminescence (point sampling) spectroscopic measurements across the visible, near and shortwave infrared for REE detection in non-invasive near-field mineral exploration. We analyse natural REE-bearing mineral samples from main REE-deposits around the world and focus on challenges such as the discrimination of overlapping spectroscopic features and the influence of the mineral type on detectability, feature position and mineral matrix luminescence. We demonstrate that the cross-validation of results from both methods increases the robustness and sensitivity, provides the potential for semi-quantification and enables the time- and cost-efficient detection of economically important REE, including $\mathrm{Ce}, \mathrm{Pr}, \mathrm{Nd}, \mathrm{Sm}, \mathrm{Eu}, \mathrm{Dy}, \mathrm{Er}, \mathrm{Yb}$ and potentially also $\mathrm{Ho}$ and $\mathrm{Tm}$.
\end{abstract}

Keywords: laser induced luminescence spectroscopy; reflectance spectroscopy; hyperspectral imaging; laser-induced fluorescence; photoluminescence; rare earth elements

\section{Introduction}

Rare earth elements (REE) are a group of 17 metallic elements, comprising the lanthanoid group, yttrium and scandium. With their valuable physical and chemical characteristics such as unique magnetic, phosphorescent and catalytic properties, they represent crucial components of many nowadays high-tech consumer products and green technologies. Due to their unique characteristics and both globally and element-wise inhomogeneous occurrence, REE were included in the European Commission's Critical Raw Materials list published in 2014 [1] and updated in 2017 [2], which set the safeguarding of a sustainable supply of raw materials within the EU as key priority. Especially Neodymium (Nd), Europium (Eu), Terbium (Tb), Dysprosium (Dy) and Yttrium $(\mathrm{Y})$, as well as Praseodymium (Pr) as a substituent for Neodymium in high-intensity permanent magnets, are commonly indicated as the most critical rare earths for both short and long term, based on 
their role in clean energy as well as supply risk [3-6]. The increasing importance of these critical raw materials for modern civilization and the associated striving for sustainability and efficiency has equally increased the need for non-invasive and fast detection methods in exploration and mining.

Common approaches for the detection of REE deposits in remote sensing rely on indirect mapping of the host lithology or associated structural features from air- or space-borne data [7-9]. For direct REE detection in the near field (sample-detector distance from centimetre up to meter scale) such as for field validation and the logging of bulk samples or drill cores, two spectroscopic approaches have independently shown their potential as alternative to time-consuming geochemical analysis, that is, reflectance and laser-induced photoluminescence (PL) spectroscopy (e.g., [10,11]). Reflectance spectroscopy refers to the analysis of the characteristic reflectance signal of a material illuminated with a spectrally broad-band light source. PL spectroscopy refers to the measurement of the luminescence of a material excited with a spectrally narrow-band light source such as a laser or high-power LED. Several studies have been published on REE characterization by one or the other method (see following chapter). Nevertheless, none prevailed as standard for reliable REE detection yet. Important reasons are the detection limitations of reflectance spectroscopy and the complicated interpretation of PL in natural minerals. A complementary approach to combine fast and straight-forward reflectance with highly sensitive PL spectroscopy could be a promising solution, however, the methods have, to our knowledge, never been compared or integrated in a combined REE detection approach.

This motivated us to investigate the detectability of REE in natural minerals using both reflectance and PL spectroscopy. As we strive to assess the benefits and obstacles of an integrated result analysis for the new task of REE mapping, we use sample-detector distances from centimetre up to meter scale. We focus on the analysis of the potential gain in interpretation reliability as well as additional constraints of the combined approach. We decided to use a preferably simple and robust methodology, as the goal is to use this technology in mining operations, such as for ore grade assessments along conveyor-belts. We separately acquire continuous-wave laser-induced luminescence measurements under three different excitation wavelengths and reflectance imagery using two recent light weight hyperspectral (HS) sensors. To evaluate detection limits and determine the influence of different sample composition, we use a geochemically well-characterized collection of natural REE-bearing samples of a wide range of mineral hosts and origins. We first analyse each acquired dataset separately to evaluate their specific characteristics. We then use the results for combined interpretation and cross-validation.

The outcomes of this study are, besides the added value in REE detectability and robustness, a required basis for the future development of an integrated sensor which allows the operational application of the combined spectroscopic approach for routine REE mapping in complex natural rock samples and drill-cores.

\section{Previous Studies of REE Spectroscopy}

\subsection{NIR-SWIR Reflectance Spectroscopy}

In contrast to transition elements, trivalent REE ions are characterized by very pronounced and sharp absorptions features. They are based on particularly confined electronic $4 \mathrm{f}$ levels, localized close to the nuclei, from which electrons can be excited by incident radiation and which are comparably unaffected by different chemical environments [12].

Early fundamental work on the reflectance spectroscopy of free $\mathrm{REE}^{2+}$ and $\mathrm{REE}^{3+}$ ions was provided by Dieke and Crosswhite [13], followed by a range of studies on the detection of single REE in synthetic compounds and the effects of grain size and crystal orientation, such as in Jassie [14] $\left(\mathrm{REECl}_{3} \cdot 6 \mathrm{H}_{2} \mathrm{O}\right.$ and $\mathrm{REEWO}_{4}$ powders), White $\left(\mathrm{REE}_{2} \mathrm{O}_{3}\right)$ [15], Ropp [16] $\left(\mathrm{REEPO}_{4}\right)$ and Weidner et al. [17] $\left(\mathrm{REE}_{2} \mathrm{O}_{3}\right)$. In parallel, foundation work on natural minerals was started such as by Adams [12], who recognized differences between the absorption patterns of light (LREE) and heavy REE (HREE)-dominated as well as mixed samples. Later, Rowan et al. [18] started to analyse specific REE in natural carbonatite samples of different origin, focusing on the investigation of the absorption 
wavelength position and depth of Nd and Sm. In 2014, 2015 and 2018, Turner et al. published a series of studies on visible/near infrared (VNIR) and shortwave infrared (SWIR) reflectance spectroscopy of important natural REE bearing mineral classes such as fluorocarbonates, phosphates and silicates from various deposits all over the world [10,19-21]. Scanning Electron Microscopy (SEM) and Electron Micro Probe Analysis (EMPA) enabled the validation of the HS measurements. By that, Turner et al. provided detailed insights into the factors influencing the occurrence and position of REE absorption features.

Parallel to the fundamental research, several papers were published that focus on the applicability of HS imaging for the detection and mapping of REE, ranging from drill core logging systems [22,23] to outcrop mapping [24] to regional geological surveys using airborne and space-borne systems [25,26]. The general consensus is that the detection success relies on a sufficient ratio between REE absorption feature depth and spectral noise. This ratio is dependent on sensor sensitivity, image processing, pixel size (as a result of target distance) and REE grade within the observed pixel. As the latter is usually low, high-quality sensors need to be operated with a sufficient spatial resolution and undergo a subsequent careful radiometric correction to enable REE detection. This has been achieved at airborne [27] and drone-borne level [28] but not yet for spaceborne data [26]. The detected REE are usually limited to a few, such as $\mathrm{Nd}$ or Sm, which occur in comparably high concentrations and feature both strong and characteristic features.

\subsection{Laser Induced NIR Luminescence Spectroscopy}

The luminescence of rare earth elements exhibits unique features which are related to the special electronic configuration of REE ions. The $4 f-4 f$ transitions show narrow emission lines while having a long lifetime [29]. In contrast to transition metals, such as $\mathrm{Fe}^{3+}$ or $\mathrm{Mn}^{4+}$, the crystal field splitting (also known as Stark level splitting), induced by the presence of different electrostatic environments for the rare earth ion, is less pronounced, mainly in the order of $100-200 \mathrm{~cm}^{-1}$. For example, the crystal field splitting of $\mathrm{Nd}^{3+}$ leads to various emission lines from $880 \mathrm{~nm}$ to $910 \mathrm{~nm}$ [30]. A result of this effect are the variable relative intensities of the split emission lines, if the rare earth ion is hosted in different matrices.

Fundamental investigations of the luminescence properties of REE by PL were conducted by Gaft et al. [31-34]. The focus was set on the detection of REE in natural minerals using laser-induced time-resolved luminescence (TRLS) with several laser excitation wavelengths and resulted in an extensive library of PL spectra and characteristic peak positions. Further studies cover not only REE luminescence but also a broad range of mineral- and transition metal luminescence and other effects such as molecular or radiation-induced centres. In 2016, Fuchs et al. built up a feature library for the detection of REE in synthetic standards, focusing especially on REE phosphates and fluorides [35]. A comprehensive study on REE luminescence in natural minerals and doped crystals was conducted by Friis [11]. Besides the detection and interpretation of REE related emissions in natural minerals and doped crystals, the study elaborated thoroughly on the high complexity of the application of luminescence for REE analysis and questions the possibility of a quantitative REE characterization using PL. A similar conclusion was reached by Lenz et al. [30], who investigated the influencing factors on the luminescence of $\mathrm{Nd}^{3+}$ in minerals, as they observed a strong relation between the intensity of certain REE sublevel peaks with both the crystal orientation of the sample as well as the polarization of incoming laser light and received emission. In 2015, Lenz et al. discussed the characteristics and advantages of laser-induced REE photoluminescence artefacts in Raman spectroscopy [36]. Beside the PL analysis of single REE-salts and mixed-REE natural mineral samples, they provided a detailed 2D PL map to illustrate the distribution of specific REE emission intensities within mineral grains.

There have been different approaches to extend the application of PL beyond the lab scale. Airborne Laser-induced Fluorescence (ALF) sensors or Fluorescence LIDAR systems have been used widely to detect and monitor organic compounds from long distances. Applications are widespread, such as the detection, mapping or monitoring of hydrocarbons, chlorophyll and dissolved organic 
matter in surface water [37-39], pollen in the atmosphere [40], green terrestrial vegetation [41,42] and photoautotrophic biodeteriogens on stone monuments [43].

The observation of inorganic compounds such as REE from larger distances or/and under ambient light is more difficult, as their cross-section with UV and NIR light is usually much lower compared to organics due to the different binding situation [44]. To receive a sufficient signal to noise ratio, high laser densities and long exposure times are needed, which usually collide with security standards and reasonable acquisition times. Therefore, most PL applications on inorganics focus on near-field measurements in a maximum range of few meters, a dark environment or a reduced spectral resolution. A prominent application is the online separation of ore and waste material and its use for mining machine control and bulk sorting [45-47]. Other application studies on inorganics comprise the characterization of mineral coatings on depleted uranium [48] and the integration of PL true colour imaging and Raman spectroscopy for the use within a rapid drill core scanner system [49]. None of these approaches were yet used for the reliable detection of REE in routine sample analytics, as their low intensity and uniquely narrow emission lines require both high spectral resolution and signal to noise ratio.

\section{Materials and Methods}

\subsection{Analysed Samples E Mineral Chemistry}

We analysed a collection of 24 naturally REE-bearing samples of different mineral species and origin. This includes samples of eleven different economically important minerals of fluorocarbonates, oxides, phosphates and silicates with varying REE content and composition (see Table 1). All samples had been embedded in epoxy-resin discs and analysed using electron microprobe (EMPA) with average $\mathrm{REE}_{2} \mathrm{O}_{3}$-detection limits of approximately $0.03 \mathrm{wt}$ \% [19]. The samples were found to be compositionally unzoned through SEM-BSE (Scanning Electron Microscope Backscattered-Electron Imaging) investigations [19]. As the spatial coverage of the conducted spectral measurements was always set with respect to the EMPA measurement spots, a high accordance in composition and concentration between the spectral and EMPA data can be assumed.

Table 1. Overview of the investigated mineral samples with formulae, origin and electron micro probe analysis (EMPA) average total rare earth element (REE) content [19]. Dominance of LREE (La to Gd) versus HREE ( $\mathrm{Tb}$ to $\mathrm{Lu}+\mathrm{Y})$ is indicated.

\begin{tabular}{|c|c|c|c|c|}
\hline Mineral Group & Mineral Species & General Formula & Sample Origin & Total $[\mathrm{REE}+\mathrm{Y}]_{2} \mathrm{O}_{3}[\%]$ \\
\hline \multirow[t]{5}{*}{ Fluoro-carbonates } & Bastnaesite & $\mathrm{CeCO}_{3} \mathrm{~F}$ & Diao Lou Shan (Sichuan, CN) & 69.35 (LREE) \\
\hline & \multirow[t]{3}{*}{ Parisite } & \multirow[t]{3}{*}{$\mathrm{CaCe}_{2}\left(\mathrm{CO}_{3}\right)_{3} \mathrm{~F}_{2}$} & Muzo (Boyacá, CO) & 58.61 (LREE) \\
\hline & & & Snowbird (Montana, US) & 58.99 (LREE) \\
\hline & & & Mexico & 48.44 (LREE) \\
\hline & Synchysite & $\mathrm{CaCe}\left(\mathrm{CO}_{3}\right)_{2} \mathrm{~F}$ & Mt. St. Hilaire (Quebec, CA) & 48.54 (LREE) \\
\hline Oxides & Fergusonite & $(\mathrm{Y}, \mathrm{REE}) \mathrm{NbO}_{4}$ & $\begin{array}{l}\text { Lyndoch Township (Ontario, } \\
\text { CA) }\end{array}$ & 14.49 (HREE) \\
\hline \multirow[t]{8}{*}{ Phosphates } & \multirow[t]{3}{*}{ Monazite } & \multirow{3}{*}{$(\mathrm{Ce}, \mathrm{La}, \mathrm{Nd}, \mathrm{Th}) \mathrm{PO}_{4}$} & Elk Mountain (Nebraska, US) & 59.00 (LREE) \\
\hline & & & Serra Verde (Para, BR) & 63.71 (LREE) \\
\hline & & & Unknown & 65.28 (LREE) \\
\hline & \multirow[t]{3}{*}{ Xenotime } & \multirow[t]{3}{*}{$(\mathrm{Y}, \mathrm{Yb}) \mathrm{PO}_{4}$} & Novo Horizonte (Bahia, BR) & 69.63 (HREE) \\
\hline & & & Novo Horizonte (Bahia, BR) & 68.26 (HREE) \\
\hline & & & Serra Verde (Para, BR) & 66.55 (HREE) \\
\hline & \multirow[t]{2}{*}{ Britholite } & \multirow[t]{2}{*}{$(\mathrm{Ce}, \mathrm{Ca})_{5}\left(\mathrm{SiO}_{4}, \mathrm{PO}_{4}\right)_{3}(\mathrm{OH})$} & Oka (Quebec, CA) & 44.09 (LREE) \\
\hline & & & Kipawa (Ontario, CA) & 53.58 (LREE) \\
\hline \multirow[t]{10}{*}{ Silicates } & Cerite & $\begin{array}{l}(\mathrm{Ce}, \mathrm{La}, \mathrm{Ca})_{9}(\mathrm{Mg}, \mathrm{Fe})\left(\mathrm{SiO}_{4}\right)_{6} \\
\left(\mathrm{SiO}_{3} \mathrm{OH}\right)(\mathrm{OH})_{3}\end{array}$ & Bastnas (Västmanland, SE) & 69.21 (LREE) \\
\hline & \multirow[t]{3}{*}{ Eudialyte } & \multirow{3}{*}{$\begin{array}{l}\mathrm{Na}_{15} \mathrm{Ca}_{6}(\mathrm{Fe}, \mathrm{Mn})_{3} \mathrm{Zr}_{3} \mathrm{SiO} \\
\left(\mathrm{O}, \mathrm{OH}, \mathrm{H}_{2} \mathrm{O}\right)_{3}\left(\mathrm{Si}_{3} \mathrm{O}_{9}\right)_{2} \\
\left(\mathrm{Si}_{9} \mathrm{O}_{27}\right)_{2}(\mathrm{OH}, \mathrm{Cl})_{2}\end{array}$} & Kipawa (Ontario, CA) & 5.25 (HREE) \\
\hline & & & Kipawa (Ontario, CA) & 4.82 (HREE) \\
\hline & & & Kipawa (Ontario, CA) & 5.63 (HREE) \\
\hline & Kainosite & $\mathrm{Ca}_{2} \mathrm{Y}_{2}\left(\mathrm{SiO}_{3}\right)_{4}\left(\mathrm{CO}_{3}\right) \cdot \mathrm{H}_{2} \mathrm{O}$ & Long Lake (New York, US) & 36.93 (HREE) \\
\hline & \multirow[t]{5}{*}{ Zircon } & \multirow[t]{5}{*}{$\mathrm{ZrSiO}_{4}$} & Green River (Wyoming, US) & 0.32 (HREE) \\
\hline & & & Mt. Malosa (Zomba, MW) & 4.83 (HREE) \\
\hline & & & Mudtank (Harts Range, AU) & 0.04 (HREE) \\
\hline & & & North Burgess (Ontario, CA) & 0.04 (HREE) \\
\hline & & & St. Peters Dome (Colorado, US) & 0.10 (HREE) \\
\hline
\end{tabular}


This allowed a validated interpretation of the observed spectral features as well as a correlation of feature intensities and REE concentrations. By that, approximate detection limits for both methods could be estimated. A reference spectral library was built from both literature derived values as well as by analysis of a suite of synthetic single-REE phosphate $\left(\right.$ REE-PO $\left.{ }_{4}\right)$ and fluoride $\left(\right.$ REE- $\left.\mathrm{F}_{3}\right)$ salts, available as partly epoxy-resin embedded single crystals. For PL data, this library was described by Fuchs et al. [35].

\subsection{Reflectance Spectroscopy-Technical Setup and Implementation}

Reflectance spectroscopy data was acquired using both point measurements and HS imagery (Figure 1). The point measurements were acquired with a Spectral Evolution PSR-3500 spectrometer (see Table 2 for detailed specifications).

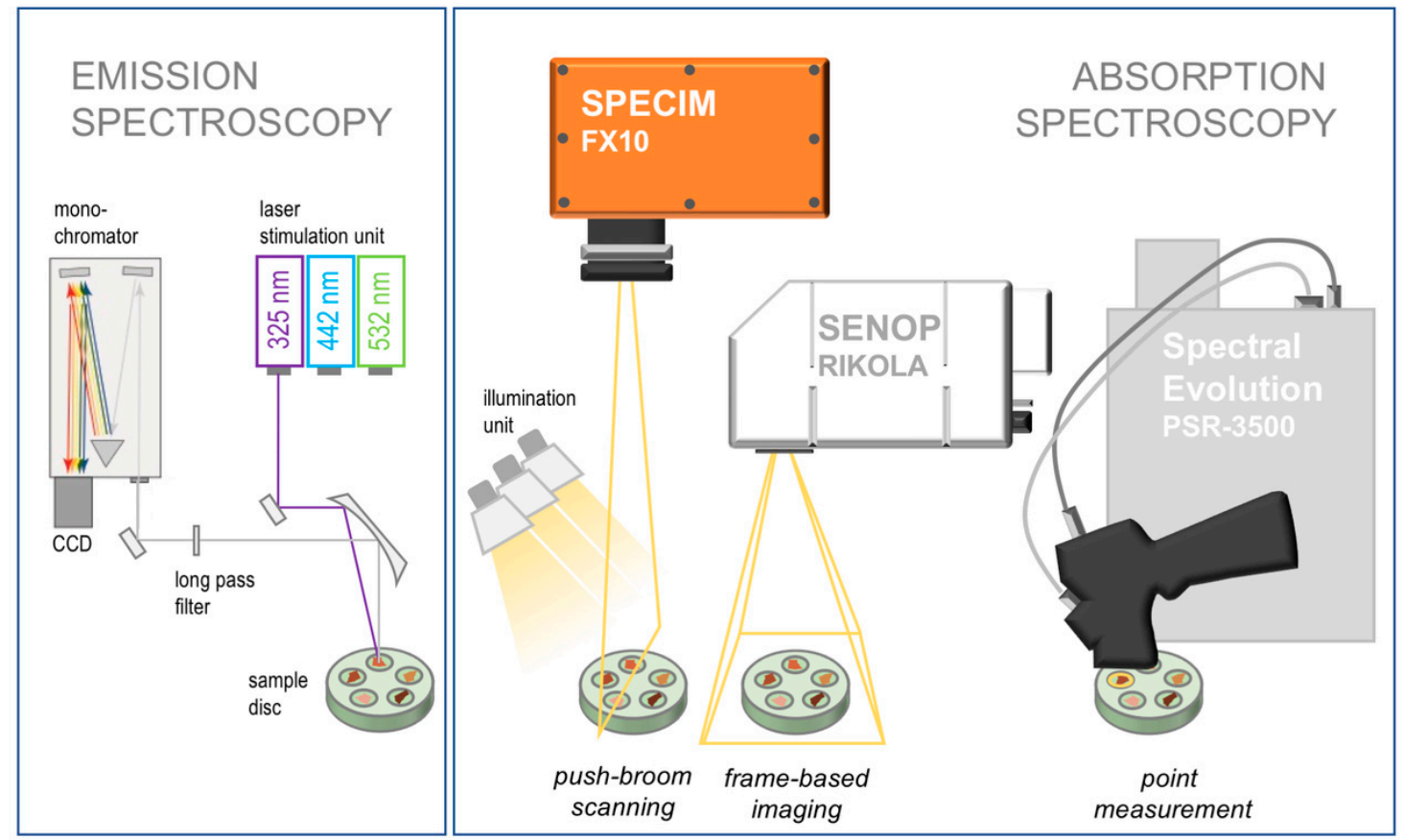

Figure 1. Schematic illustration of the technical setup (not to scale).

An internal white light source and intermediate white target calibrations (Spectralon SRS-99) ensured stable measurement conditions and resulted in accurate and highly resolved spectra. The signal was integrated over 10 single measurements at a target spot of around $3 \mathrm{~mm}^{2}$. Due to the very small size of some of the investigated mineral grains, which can fall far below the measurement spot diameter, a light blocking foil was used as background to reduce the influence of ambient light. An influence of the surrounding resin is still possible and needs to be considered for the respective samples. In contrast to point measurements, HS imagery adds a spatial component to the reflectance data by providing a spectrum for each pixel of a measured scene. Thus, spectral information can be set into a spatial context and used to provide mineral or element abundance maps. However, a high spatial resolution often goes along with a loss in spectral sampling and/or wavelength detection range, as the imager must be able to acquire and process a large batch of spectra simultaneously. In order to test the applicability of common commercial low-to-medium priced HS imagers for the mapping of REEs in natural minerals, the data was acquired using both the frame-based Senop Rikola HS Camera as well as the push-broom Specim FX10 (see Table 2 for detailed specifications). The spatial resolution of both sensors is sufficient to separate smaller mineral grains, while the covered wavelength ranges include most of the relevant REE absorption features. The spectral resolution in VNIR is coarser compared to spectrometer point measurements but is usable to detect the most prominent absorption features. During the image acquisition, a uniform illumination over the whole sample batch was needed to 
ensure the comparability of REE absorption depths in different samples. Therefore, the imaging was conducted using the sample illumination unit of the Specim SisuRock drill-core scanner, which features two rows of full-spectrum halogen spotlights, uniformly illuminating an area of $\sim 640 \times 200 \mathrm{~mm}$.

Although the Rikola sensor theoretically features a similar spatial resolution to the FX10 at the same working distance, its significantly lower SNR results in a noisier image. To still deliver a sufficient image quality even for very small samples, it was required to operate the sensor at reduced distance. This resulted in optimal imaging distances of about $430 \mathrm{~mm}$ for the Rikola and $600 \mathrm{~mm}$ for the FX10. However, as the optics of the Rikola are fixed with an optimal focusing distance of approximately $600 \mathrm{~mm}$ to infinity, a minor but acceptable blur was noticeable within the data.

Table 2. Visible/near infrared (VNIR) HS sensor characteristics. ${ }^{*} \mathrm{FWHM}=$ full width at half maximum, ${ }^{* *}$ SNR values estimated for each spectral channel as ratio of mean and standard deviation of 20-40 spectra acquired under uniform conditions.

\begin{tabular}{|c|c|c|c|}
\hline & $\begin{array}{l}\text { Spectral Evolution } \\
\text { PSR-3500 }\end{array}$ & Senop Rikola & Specim FX 10 \\
\hline sensor type & $\begin{array}{l}\text { portable field } \\
\text { spectrometer }\end{array}$ & frame-based imager & push broom scanner \\
\hline data dimension & $1 \mathrm{px}$ & $1010 \times 1010 \mathrm{px}$ frame & 1024 px line \\
\hline wavelength range & $350-2500 \mathrm{~nm}$ & $500-900 \mathrm{~nm}$ & 400-1000 nm \\
\hline spectral resolution $\left(\mathrm{FWHM}^{*}\right)$ & $\begin{array}{l}3.5 \mathrm{~nm}(\mathrm{VNIR}) \\
7-10 \mathrm{~nm}(\mathrm{SWIR})\end{array}$ & $10 \mathrm{~nm}$ & $5.5 \mathrm{~nm}$ \\
\hline $\begin{array}{l}\text { estimated peak signal-to-noise } \\
\text { ratio }(\mathrm{SNR})^{* *}\end{array}$ & $600: 1$ & $150: 1$ & $600: 1$ \\
\hline $\begin{array}{l}\text { spatial resolution (length of } \\
\text { quadratic pixel) }\end{array}$ & $2 \mathrm{~mm}$ & $\begin{array}{l}\text { distance dependent (here: } 0.14 \\
\mathrm{~mm} \text {, slightly defocused) }\end{array}$ & $\begin{array}{l}\text { distance dependent } \\
\text { (here: } 0.41 \mathrm{~mm} \text {, focused) }\end{array}$ \\
\hline spectral bands & 1024 & up to 380 & 224 \\
\hline
\end{tabular}

\subsection{PL Spectroscopy-Technical Setup E Implementation}

The PL spectroscopy measurements were conducted in a darkroom lab to avoid the influence of ambient light on the measurement result. The samples were investigated under three different continuous wave laser excitation wavelengths to analyse potential REE detection variabilities (Figure 1). The used laser excitation wavelengths, respective spot sizes and resulting power densities are given in Table 3. The power of the respective laser beams has been tuned to $4 \mathrm{~mW}$ for all lasers. The luminescence signal of the excited sample is dispersed by an Acton SP2560 Triple-Grating Monochromator (300 gr/mm grating, blazed at $750 \mathrm{~nm}$ ) and recorded by a Princeton Instruments SPEC-10:100BR_eXcelon CCD-Camera (Figure 1). The data are recorded in up to 5743 channels for a full spectrum from 340 to $1080 \mathrm{~nm}$. The measurements with 325 and $442 \mathrm{~nm}$ laser excitation were conducted in two single measurements, differing in the employed long-pass filters to suppress excitation laser light on the one hand and spectral second order effects from the monochromator gratings on the other hand. The two measurements are later merged in the post-processing of the spectral data [35]. Due to limited sensitivity at extreme wavelengths, data under 400 and over $1050 \mathrm{~nm}$ is excluded from the analysis.

Table 3. Laser specifications. Beam diameter is given as $1 / \mathrm{e}^{2}$ of a gaussian fit. The power density is calculated assuming a constant power distribution over the given beam diameter.

\begin{tabular}{lll}
\hline Laser Wavelength (Laser Type) & Beam Diameter & Power Density \\
\hline $325 \mathrm{~nm}$ (Kimmon He-Cd-laser) & $185 \mu \mathrm{m}$ & $14.58 \mathrm{~W} / \mathrm{cm}^{2}$ \\
$442 \mathrm{~nm}$ (Kimmon He-Cd-laser) & $170 \mu \mathrm{m}$ & $16.73 \mathrm{~W} / \mathrm{cm}^{2}$ \\
$532 \mathrm{~nm}$ (diode-pumped frequency-doubled Nd:YAG) & $143 \mu \mathrm{m}$ & $26.93 \mathrm{~W} / \mathrm{cm}^{2}$ \\
\hline
\end{tabular}




\section{Results}

\subsection{Reflectance Spectroscopy}

Reference reflectance spectra and positions of characteristic absorption features for each REE were determined from the single-REE salt suites using both lightweight HS imagers (see example in Figure 2) and were validated by point spectrometer data. This measurement redundancy was important to consider possible sensor specific disturbances such as feature shifts and ensure valid feature positions. The resulting feature tables were complemented with additional feature positions reported in the literature $[15,16,18,19]$. The resulting library shows a potential detectability of $\operatorname{Pr}^{3+}, \mathrm{Nd}^{3+}, \mathrm{Dy}^{3+}$, $\mathrm{Ho}^{3+}, \mathrm{Er}^{3+}$ and $\mathrm{Tm}^{3+}$ for both Rikola and FX10. An overview on the most characteristic and best observable REE features in the VNIR is shown in Figure 3a. The most characteristic absorption features of $\mathrm{Sm}^{3+}, \mathrm{Eu}^{3+}, \mathrm{Tb}^{3+}$ and $\mathrm{Yb}^{3+}$ are located outside the wavelength coverage of both VNIR imaging spectrometers but $\mathrm{Sm}^{3+}$ and $\mathrm{Yb}^{3+}$ can be reliably detected at the extended wavelength coverage of the hand spectrometer. A detection of these elements using a SWIR HS camera should therefore be possible, as documented in Turner [19]. However, the absorption features of $\mathrm{Eu}^{3+}$ and $\mathrm{Tb}^{3+}$ expected in the VNIR are weak and often hardly visible, which questions their potential detectability with reflectance spectroscopy. The same accounts for $\mathrm{Sc}^{3+}, \mathrm{Y}^{3+}, \mathrm{La}^{3+}, \mathrm{Ce}^{3+}, \mathrm{Gd}^{3+}$ and $\mathrm{Lu}^{3+}$, which are not detectable with any of the used devices, as they do not absorb at all in the VNIR and SWIR wavelength region due to their respective electronic configuration [15].
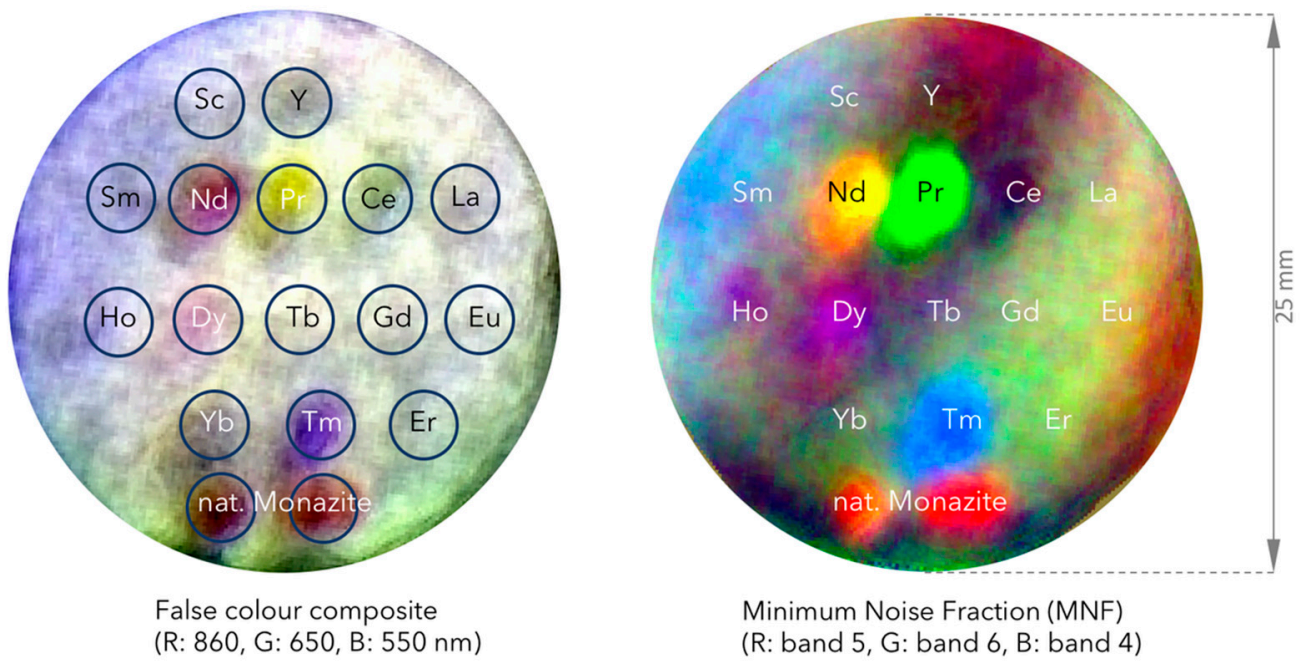

Figure 2. HS imaging of an REE-PO4 standard sample disc using a lightweight Senop Rikola sensor. The data are displayed as false colour and minimum noise fraction (MNF) [50] composite.

After the compilation of the absorption feature catalogue, the mixed-REE natural sample batches were analysed and imaged with the same procedure. In Figure 3b, two example image spectra for both LREE- and HREE-dominated samples are shown. The given EMPA-derived REE-concentrations represent a mean of five single EMPA measurements of the respective sample [19]. Low standard deviations suggest relatively uniform values for chemical composition and $\mathrm{REE}^{3+}$-concentrations within the analysed mineral grain. A comparison of the spectral datasets of the Rikola and FX10 sensor with known REE absorption feature positions pictures a distinct but constant spectral shift of the Rikola data to higher wavelengths by about $10 \mathrm{~nm}$ (Figure 3b), which might originate from an internal sensor misalignment and must be considered for data interpretation. The spectral gap between the two built-in sensors in the Rikola generates an additional spectral disturbance observed as a sharp artefact around 636-650 nm (Figure 3b). Despite the mentioned spectral perturbations, the shapes of the received spectra for both sensors match well, however, the spectral quality of the FX10 data exceeds the Rikola data due to higher spectral resolution (FWHM) and Signal-to-Noise-Ratio (SNR) (Table 2). 


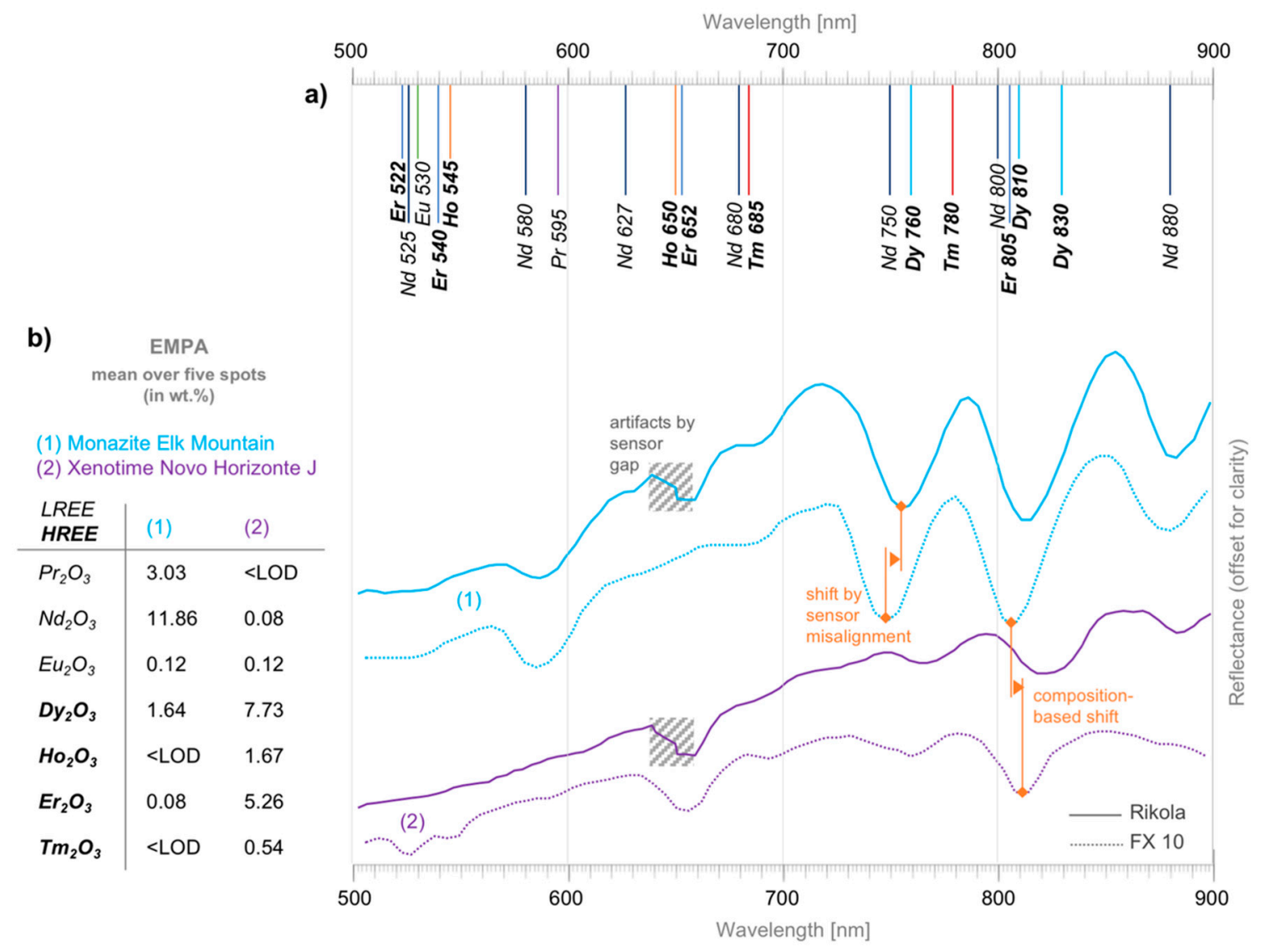

Figure 3. (a) Position of the most characteristic REE absorption features in the VNIR range according to the analysis of single-REE salts and literature review, (b) extracted spectra from HS imaging of natural mixed REE mineral samples using two different HS sensors. Sample (1) represents LREE-enriched grains, while (2) is HREE-dominated. EMPA analysis results are given as mean of a series of five measurements (<LOD: below Limit of Detection).

The depicted spectra of LREE-enriched monazite and britholite are clearly dominated by the absorption features of $\mathrm{Nd}^{3+}$ and $\mathrm{Pr}^{3+}$. Especially the prominent absorptions around 580, 750, 800 and $880 \mathrm{~nm}$ are very characteristic and easily detectable. The exact positions of the absorption minima vary slightly according to the present quantities of the main absorbents, such as $\mathrm{Pr}^{3+}, \mathrm{Nd}^{3+}, \mathrm{Er}^{3+}$ and $\mathrm{Dy}^{3+}$, which each contribute to the respective observed absorption feature. A good example is the shift of the feature around $810 \mathrm{~nm}$, which is influenced by absorptions of $\mathrm{Nd}^{3+}(800 \mathrm{~nm}), \mathrm{Er}^{3+}(805 \mathrm{~nm})$ and $\mathrm{Dy}^{3+}$ $(810$ and $830 \mathrm{~nm})$. Both HS sensors are not able to separate these features, so they result in a single deep minimum and its exact position is dependent on the abundance of the three REE. For example, the spectrum of the monazite sample with low $\mathrm{Er}^{3+}$ and $\mathrm{Dy}^{3+}$ content features a mixed but clearly $\mathrm{Nd}$-dominated absorption at $802 \mathrm{~nm}$ (Figure 3b). In contrast, the spectrum of the HREE-enriched xenotime sample is characterized mainly by $\mathrm{Er}^{3+}$ and $\mathrm{Dy}^{3+}$ related features. Here, a distinct shift of the feature to longer wavelengths and towards the pure $\mathrm{Dy}^{3+}$ absorption can be seen $(812 \mathrm{~nm})$. Features solely related to LREE, such as the mixed $590 \mathrm{~nm}$ absorption of $\mathrm{Nd}^{3+}$ and $\mathrm{Pr}^{3+}$, are weak or not observable in this sample.

To illustrate the correlation between absorption shift and the relative quantity of the respective absorbing REE, a Minimum Wavelength Map [51] of the REE related absorption around $810 \mathrm{~nm}$ was conducted. With this approach, the wavelength position and depth of the deepest signal minimum within a defined wavelength window (here: $790-860 \mathrm{~nm}$ ) is determined for each pixel and plotted after as wavelength position map (see Figure 4a). 


\section{(a)

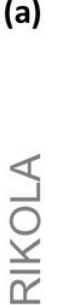

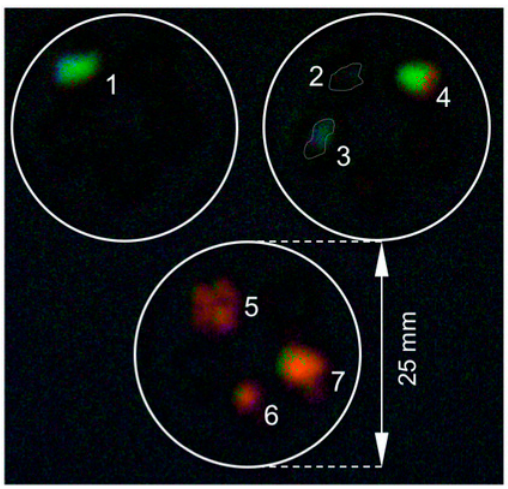

1-Britholite 2,3-Xenotime 4-Monazite 5- Bastnaesite 6,7-Parisite

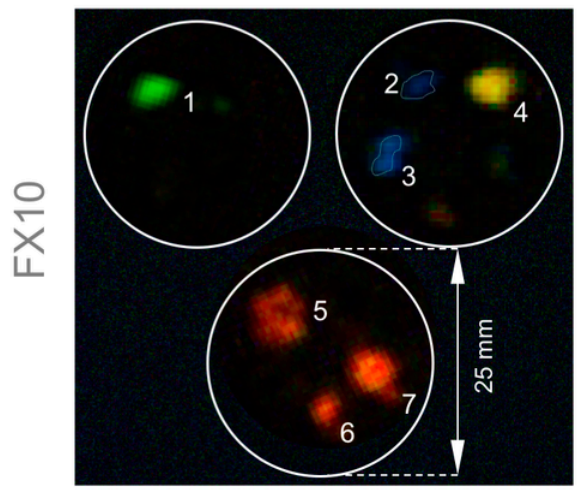

(b)
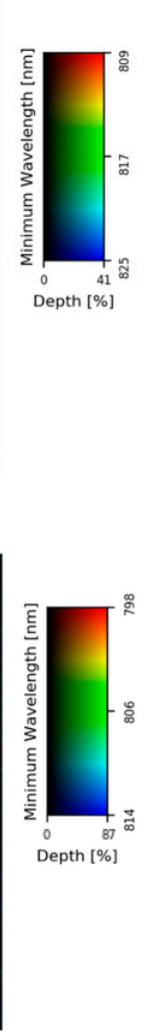
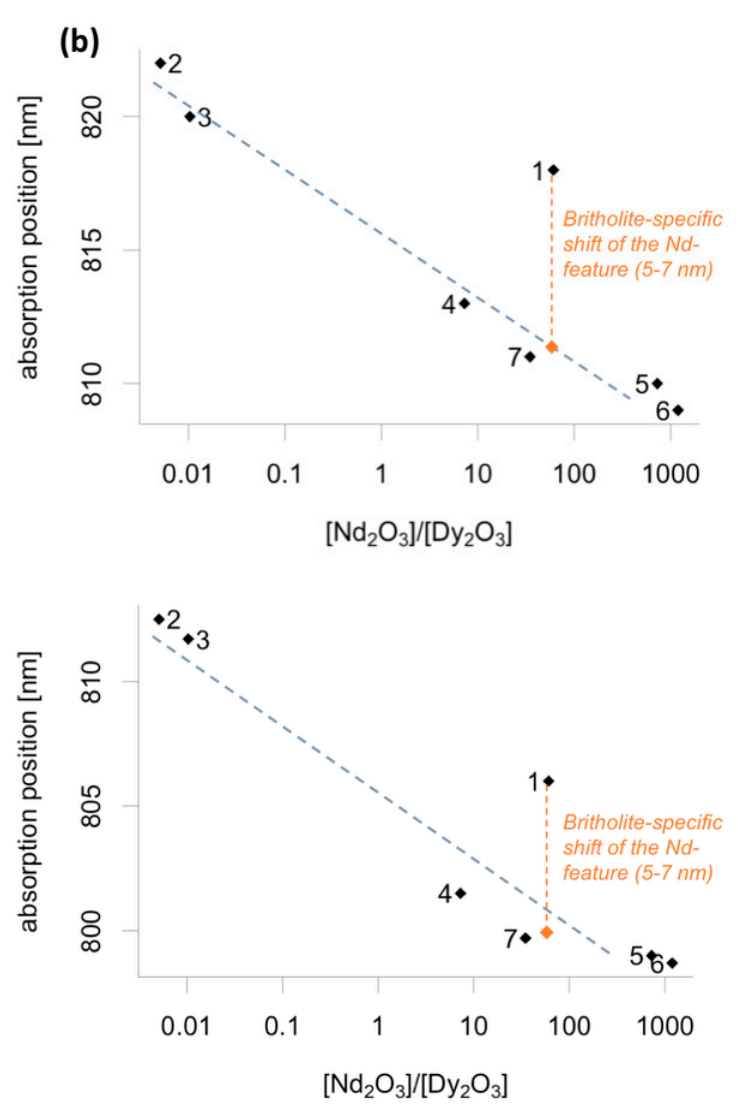

Figure 4. Relation between relative abundances of different REE and observed absorption feature position for both used HS imagers: (a) Reflectance minimum wavelength mapping in the range of 790 and $860 \mathrm{~nm}$ for three natural mineral sample batches and (b) scatter plot between observed minimum wavelength and the respective ratio of EMPA derived $\mathrm{Nd}^{3+}$ and $\mathrm{Dy}^{3+}$ concentrations for seven sample grains marked in (a).

The wavelength position of the reflectance minimum is determined using a 5 th order polynomial fit of the investigated spectral range. Even if such high-order polynomial may feature possible instability in the presence of spectral distortions, Murphy et al. [52] shows that this method delivers a good accuracy and reliability of the result, as it excludes artificial position shifts due to spectral noise. In Figure $4 \mathrm{~b}$ the shifts of the absorption minimum wavelength of the respective samples are plotted against the ratio of $\mathrm{Nd}_{2} \mathrm{O}_{3}$ (LREE) and $\mathrm{Dy}_{2} \mathrm{O}_{3}$ (HREE). For most of the samples, a very good correlation between composition and shift can be observed. Highly LREE-rich samples (numbers 5 and 6 , in red) can be easily distinguished from HREE-rich samples (numbers 2 and 3, in blue). Furthermore, LREE-HREE-mixed samples can be characterized and compositionally arranged in between (numbers 4 and 7, ranging from orange to green according to LREE-HREE-ratio). Only one sample seems to be off the trend and features a strong shift to larger wavelengths despite its comparably low Dy concentration (Figure 4, sample number 1). This aspect can be explained as the hosting sample is britholite, which is known for high systematic shifts of occurring $\mathrm{Nd}^{3+}$ features to longer wavelengths by about $5-7 \mathrm{~nm}$ [19]. Taking this into account, the remaining shift indicates an LREE-HREE-ratio in the range of sample number 7 , which correlates to the EMPA results. The resulting graph proves a clear correlation between the observed minimum position and the $\mathrm{Nd}_{2} \mathrm{O}_{3}-\mathrm{Dy}_{2} \mathrm{O}_{3}$-ratio. However, this relation is not assumed to be linear, especially as the individual ratio between concentration and resulting absorption depth is not identical for different REE. Still, it opens up the possibility for both an indirect detection of REE with features hidden by neighbouring absorptions and the semi-quantitative estimation of the involved REE. A few REE remain indiscernible in natural minerals despite being detectable in single-REE salts. For example, $\mathrm{Eu}^{3+}$ showed weak features in all analysed 
single-REE salts, which are situated mainly in the lower VNIR (380-600 nm) and the upper SWIR (especially 1900-2200 nm) [14-16]. However, within natural samples, the detection of $\mathrm{Eu}^{3+}$ becomes nearly impossible due to a strong overlap of the weak VNIR features with other highly visible REE such as $\mathrm{Nd}^{3+}, \mathrm{Er}^{3+}$ and $\mathrm{Ho}^{3+}$. The characteristic SWIR features around 1900-2100 nm (not shown here) may in mixed pixels additionally overlap and be confused with nearby characteristic broad features of $\mathrm{OH} / \mathrm{H}_{2} \mathrm{O}$ (centre wavelength around $1900 \mathrm{~nm}$ ). Similar to $\mathrm{Eu}^{3+}$, the features of $\mathrm{Tb}^{3+}$ were hardly visible and highly ambiguous, which excludes both elements from the list of REE potentially detectable with reflectance spectroscopy.

\subsection{PL Spectroscopy}

Reference PL spectra and positions of characteristic emission features for each REE were previously determined using a series of single-REE salts [35]. The resulting feature library was merged and extended with similar and additional feature positions reported in the literature [34,53]. Results showed a potential robust detectability of $\mathrm{Nd}^{3+}, \mathrm{Sm}^{3+}, \mathrm{Eu}^{3+}, \mathrm{Yb}^{3+}, \mathrm{Dy}^{3+}, \mathrm{Er}^{3+}$ and $\mathrm{Tb}^{3+}$ when using continuous-wave laser-induced fluorescence with excitation wavelengths of 325,442 and $532 \mathrm{~nm}$ on single-REE salts. The same experimental setup was used in the current study to analyse the described natural REE-bearing mineral sample suite. Several factors and effects were observed accompanying mixed samples, which may support or hinder a robust detection of specific REE. These effects need to be considered during data interpretation and are described in more detail in the following.

\subsubsection{Influence of the Excitation Wavelength}

Due to the discrete nature of the REE $4 \mathrm{f}-4 \mathrm{f}$ intra-configurational transitions, direct optical excitation of the typical REE luminescence lines is possible only for excitation wavelengths in the visible range which are specific to each REE [54]. Broad-band, more unspecific, excitation is only possible for high excitation energies, reaching the charge transfer bands or the host's conduction band, which may be far in the UV range. Thus, by stimulating using an appropriate wavelength, specific REE luminescence may be enhanced or suppressed, which opens up the possibility for (1) the discrimination of overlapping REE features and (2) the suppression of broad emissions originating from non-REE impurities and crystal structure defects. The influence of the employed excitation wavelength on the detectable REE is displayed for an analysed xenotime sample in Figure 5. For some REE, such as $\mathrm{Yb}^{3+}, \mathrm{Er}^{3+} \mathrm{or} \mathrm{Ho}^{3+}$, the excitation wavelength influences mainly the feature intensity or the occurrence and position of sub-level peaks. Others, such as $\mathrm{Dy}^{3+}$ and $\mathrm{Sm}^{3+}$ show a clearer dependency on the chosen excitation wavelength and are suppressed or not visible at other excitation wavelengths. For those elements featuring a variety of strong peaks that often superpose other REE, this excitation wavelength dependency demonstrates a possibility to reveal hidden REE peaks or discriminate and interpret overlapping features.

The excitation wavelength dependency of broad matrix emissions is shown on spectra of eudialyte and zircon (Figure 6). In all analysed eudialyte samples, several broadband luminescence features occur, whose visibilities are dependent on the respective excitation wavelength. At this, a strong $\mathrm{Ce}^{3+}$-luminescence at $380-400 \mathrm{~nm}$ can be observed only at $325 \mathrm{~nm}$ excitation wavelength (Figure 6a). However, at longer excitation wavelengths a previously not visible broadband feature appears at $600 \mathrm{~nm}$ (Figure 6c) and most probably originates from the substitution of $\mathrm{Ca}^{2+}$ with $\mathrm{Mn}^{2+}$ within the crystal [55]. A respective MnO content of $\sim 1.4 \mathrm{wt} . \%$ is validated by EMPA data for this sample. A third broadband luminescence at $505 \mathrm{~nm}$, possibly related to the sample embedding epoxy resin, occurs only with blue excitation. It overlaps with the slightly weaker $600 \mathrm{~nm}$ luminescence, which appears as shoulder (Figure 6b). 


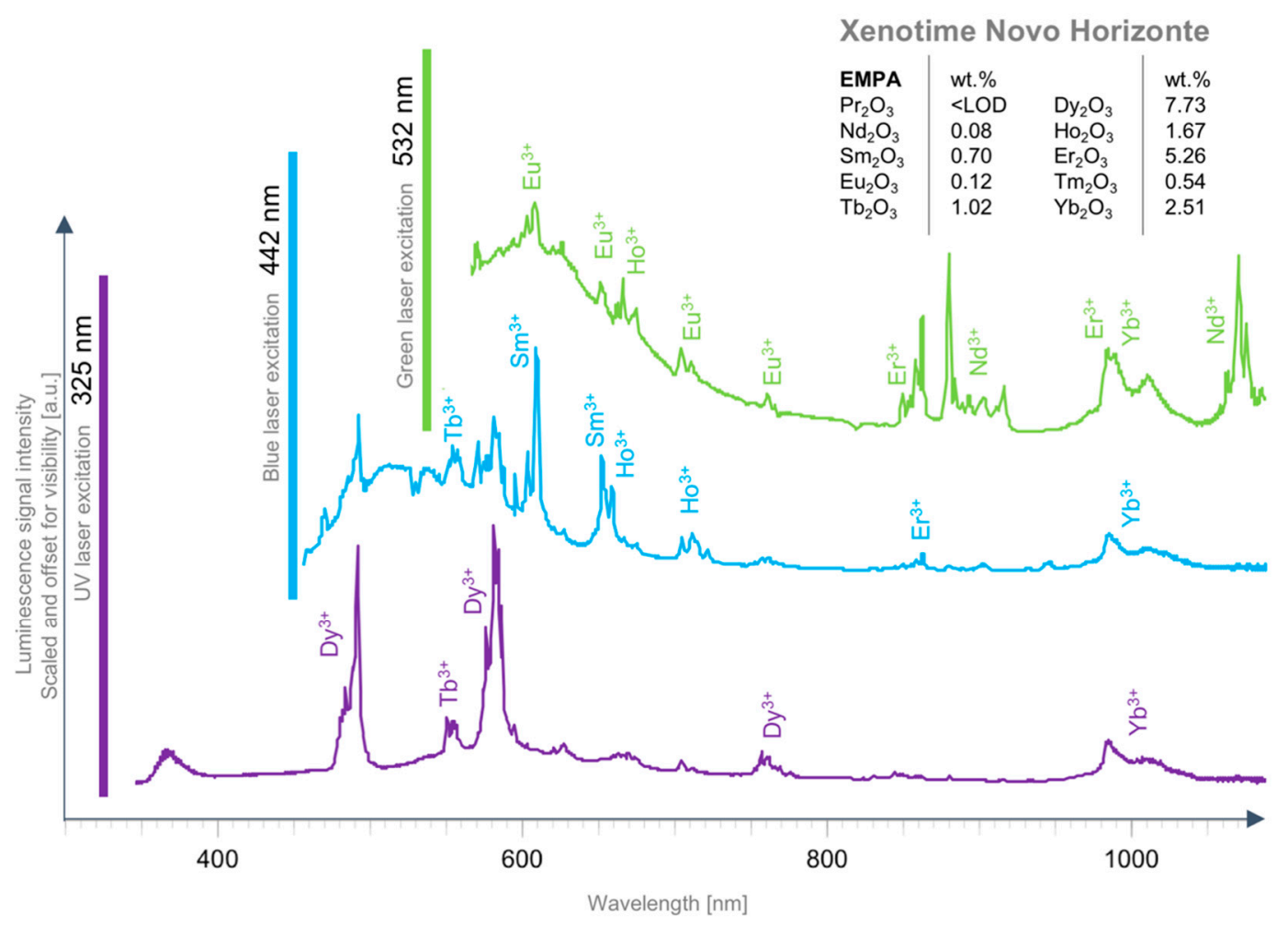

Figure 5. REE and matrix emission variability in a xenotime sample are displayed as a function of three different laser excitation wavelengths. Selected REE emissions have been labelled according to reference feature positions (see text, Section 4.2.).

The observed broad emissions in zircon are many and often of uncertain origin but commonly dependent on specific excitation wavelengths, such as:

(I) A strong and broad emission with a centre wavelength of 580 to $590 \mathrm{~nm}$ visible mainly at $325 \mathrm{~nm}$ excitation (Figure 6d, I) and substantially decreased at longer excitation wavelengths (Figure 6e,f, I). It originates probably in radiation damage centres that cause the characteristic red-brown colour of many zircons and is decreased in intensity for longer excitation wavelengths [34,56].

(II) A broadband near-infrared luminescence (centre-wavelength around $780 \mathrm{~nm}$ ) was observed in some zircon samples under $325 \mathrm{~nm}$ (Figure 6d, II) and $442 \mathrm{~nm}$ excitation (Figure 6e, II) and might be related to $\mathrm{Fe}^{3+}$ or $\mathrm{Ti}^{3+}[34,56]$. It nearly disappears under $532 \mathrm{~nm}$ excitation (Figure 6f, II).

(III) A strong green luminescence appears around $510 \mathrm{~nm}$ under $442 \mathrm{~nm}$ excitation (Figure 6e, III), which in zircon is usually connected to the luminescence centres of $\mathrm{UO}_{2}{ }^{2+}$ [57]. It may also originate from the sample embedding epoxy resin, which shows a very similar feature. At $325 \mathrm{~nm}$ excitation, this centre is weak and hardly observable, as it is nearly covered by the stronger orange broadband luminescence (Figure 6d, I). 

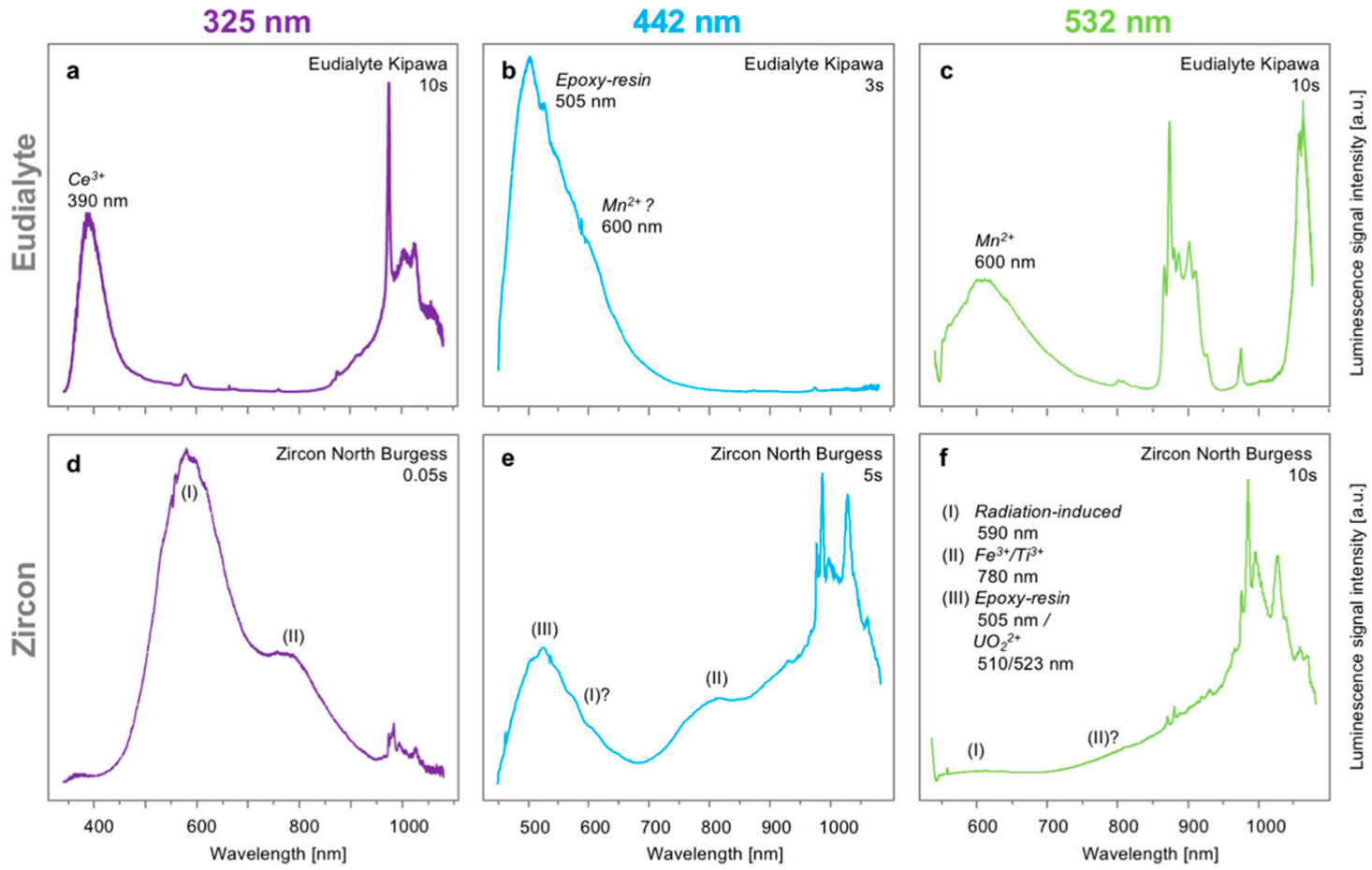

Figure 6. Interpretation of variable broad emission features as a function of excitation wavelength in $(\mathbf{a}-\mathbf{c})$ eudialyte and $(\mathbf{d}-\mathbf{f})$ zircon samples. Excitation wavelengths are indicated on top of each plot group.

\subsubsection{Influence of the Mineral Type}

The spectral position of specific REE emission lines were found to be constant within a few nanometres, which reasons in the REE $4 \mathrm{f}-4 \mathrm{f}$ transitions that are generally not affected by their chemical environment. However, the specific Stark-level peak positions and relative intensities varied heavily between host minerals and slightly between samples of the same host mineral from different geological localities (Figure 7). This observation coincides with statements in the literature, such as in References [58] and [36]. Accordingly, the local structural environment of the $\mathrm{REE}^{3+}$-ion decides on the splitting of the recorded emission peaks, which is also known as crystal-field dependent Stark's splitting. A respective $\mathrm{REE}^{3+}$ sub-level peak database would open up the possibility to a fingerprint-like detection of the host mineral [36]. Figure 7 displays the variability of the observed sub-level peaks at the characteristic $\mathrm{Nd}^{3+}$ feature centre wavelength of $890 \mathrm{~nm}[34,53]$ for the investigated samples in dependency of the excitation wavelength and gives an example on such a potential database. Remarkable are the bandwidth of occurring sub peak positions and the overall similarity of spectral shape and sub peak positions within one mineral type or even group. Similar patterns were observed for many mineral types such as for monazite or eudialyte. Few minerals such as britholite showed a higher variability, which in the current case might be related to abundant REE-bearing apatite in the britholite samples from Oka.

In some samples such as xenotime or kainosite, characteristic $\mathrm{Er}^{3+}$ features around $855 \mathrm{~nm}$ become apparent, which interfere with the investigated $\mathrm{Nd}^{3+}$ sub-level peaks. A high variability in response to different excitation wavelengths is given, ranging from no change (monazite) over differing spectral shape (britholite) up to a suppression of detectability (zircon). 
$325 \mathrm{~nm}$

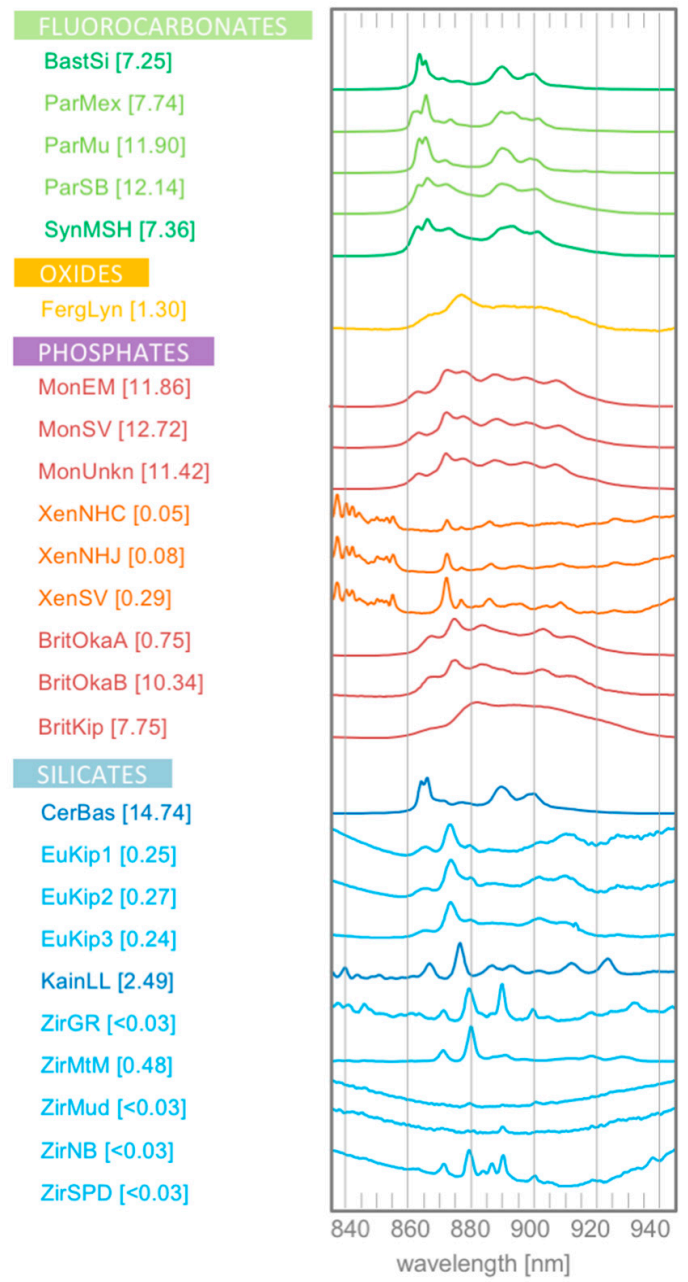

$442 \mathrm{~nm}$

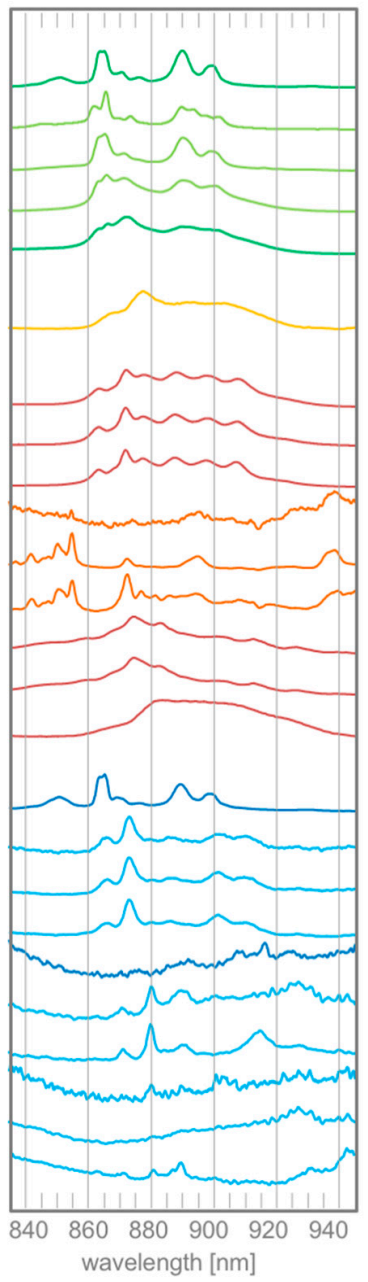

$532 \mathrm{~nm}$

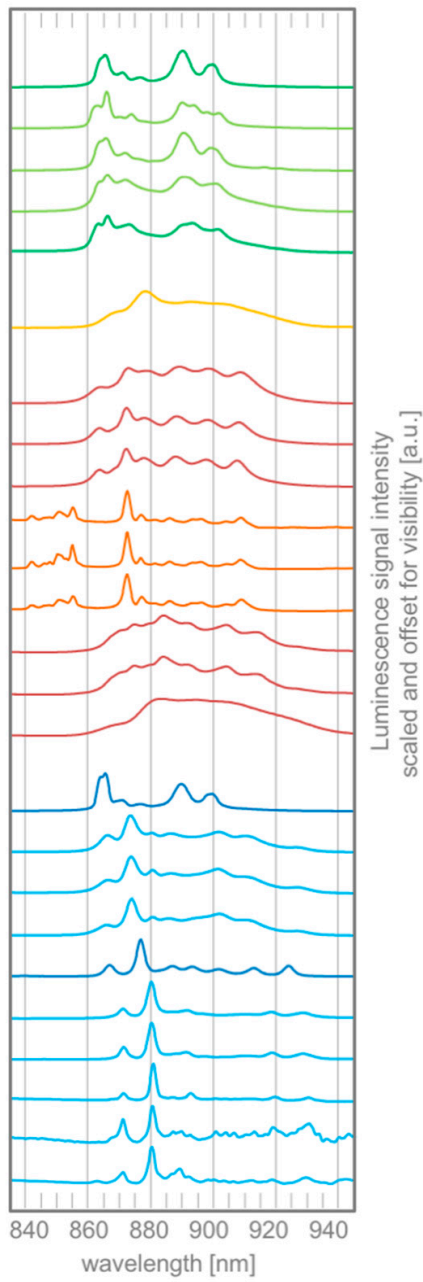

Figure 7. Variability of Stark-level emission peaks for the literature reported $\mathrm{Nd}^{3+}$ feature centre wavelength of $890 \mathrm{~nm}[34,53]$ for different samples and excitation wavelengths. EMPA derived $\mathrm{Nd}_{2} \mathrm{O}_{3}$-concentrations are given in squared brackets in wt.\%. Excitation wavelengths are indicated on top of each plot group.

\subsubsection{REE Absorption Effects in PL Spectra}

For samples and excitation wavelengths where intense and broad emissions occur around 500 to $800 \mathrm{~nm}$, specific absorptions effects were likely to be observed within the PL signal. For each case, they could be certainly assigned to occurring REE (Figure 8). The features originate mainly from $\mathrm{Nd}^{3+}$, which is known to show extremely distinct absorption features in this wavelength region and to a lesser degree $\mathrm{Pr}^{3+}, \mathrm{Dy}^{3+}$ and $\mathrm{Er}^{3+}$, which strongly overlap with the $\mathrm{Nd}^{3+}$ features. While providing additional information on these four elements, this phenomenon also holds a crucial disadvantage. Weak but characteristic emission features of other REE in this wavelength range can be either annihilated completely or masked to an extent, where they are not discriminable anymore from, for example, artificial peaks originating from two adjacent absorptions. For example, the two most characteristic $\mathrm{Pr}^{3+}$ emission features are located at 480 and $599 \mathrm{~nm}$ and are often completely masked by strong $\mathrm{Nd}^{3+}$-related absorptions around 475 and $580 \mathrm{~nm}$, Dy ${ }^{3+}$-related absorptions at $476 \mathrm{~nm}$ and the $\mathrm{Pr}^{3+}$-related absorption around $593 \mathrm{~nm}$ (see also Figure 3a). This crucially affects the general detectability with PL spectroscopy of all REE that are solely detectable by peaks in the respective wavelength ranges, such as $\mathrm{Tm}^{3+}$ and weakens the detectability robustness of REE with characteristic peaks in the respective wavelength ranges, such as $\mathrm{Pr}^{3+}, \mathrm{Sm}^{3+}$ and $\mathrm{Ho}^{3+}$. Variation of the excitation 
wavelength can be used to avoid broad-band emission of the mineral host and by that to reduce the influence of absorption on the PL signal (see also Section 4.2.1).

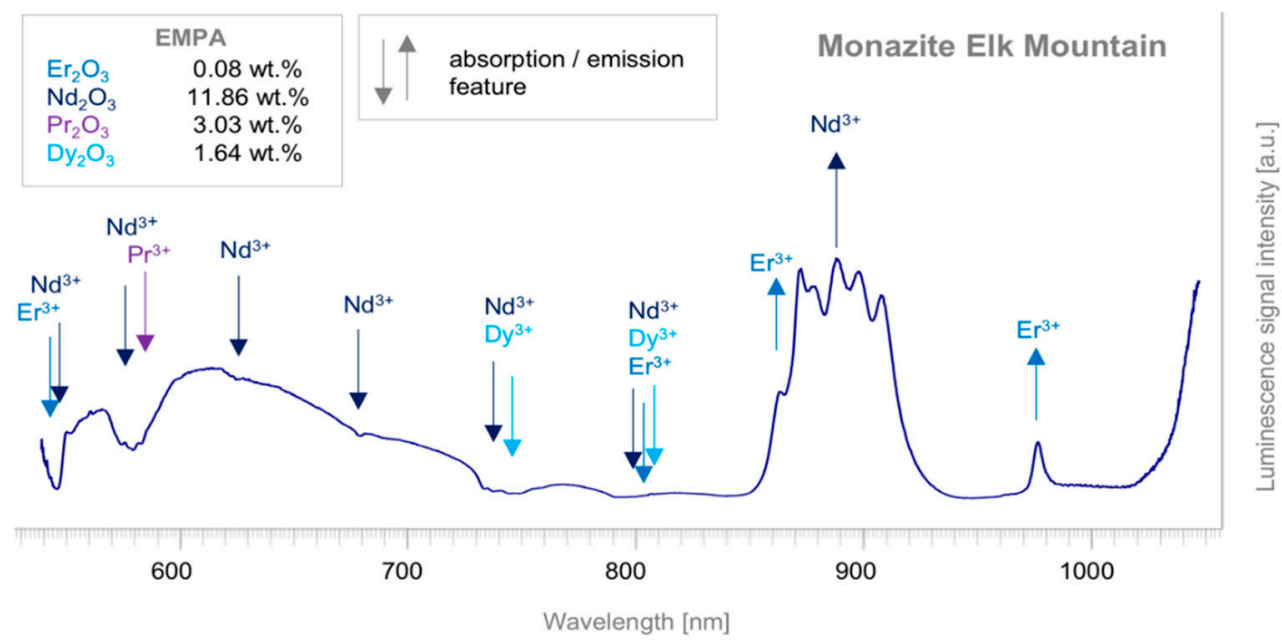

Figure 8. Occurrence of REE absorption features within PL spectra on the example of Monazite Elk Mountain sample. Significant features are labelled with the most probably related REE (also compare Figure 3a). Laser excitation: $532 \mathrm{~nm}$.

\section{Discussion and Cross-Method Considerations}

A concise overview on the features, advantages and weaknesses of both reflectance and PL spectroscopy is given in Table 4 and discussed further in detail in following sections.

Table 4. Concluding overview on the capabilities of reflectance and PL spectroscopy for near-field REE detection.

\begin{tabular}{|c|c|c|}
\hline & Reflectance Spectroscopy & PL Spectroscopy (325/442/532 nm Excitation) \\
\hline Detectable REE in single-REE salts & $\begin{array}{l}\text { Robust: } \mathrm{Pr}^{3+}, \mathrm{Nd}^{3+}, \mathrm{Sm}^{3+}, \mathrm{Dy}^{3+}, \\
\mathrm{Ho}^{3+}, \mathrm{Er}^{3+}, \mathrm{Tm}^{3+}, \mathrm{Yb}^{3+} \\
\text { Weak: } \mathrm{Eu}^{3+}\end{array}$ & $\begin{array}{l}\text { Robust: } \mathrm{Ce}^{3+}, \mathrm{Pr}^{3+}, \mathrm{Nd}^{3+}, \mathrm{Sm}^{3+}, \mathrm{Eu}^{3+}, \mathrm{Tb}^{3+} \\
\mathrm{Dy}^{3+}, \mathrm{Er}^{3+}, \mathrm{Yb}^{3+} \\
\text { Weak: } \mathrm{Ho}^{3+}, \mathrm{Tm}^{3+}\end{array}$ \\
\hline $\begin{array}{l}\text { Detectable REE in mixed-REE } \\
\text { natural samples }\end{array}$ & $\begin{array}{l}\text { Robust: } \mathrm{Nd}^{3+}, \mathrm{Sm}^{3+}, \mathrm{Dy}^{3+}, \mathrm{Yb}^{3+} \\
\text { Ambiguous (detectable by feature } \\
\text { shift): } \mathrm{Pr}^{3+}, \mathrm{Ho}^{3+}, \mathrm{Er}^{3+}, \mathrm{Tm}^{3+}\end{array}$ & $\begin{array}{l}\text { Robust: } \mathrm{Ce}^{3+}, \mathrm{Nd}^{3+}, \mathrm{Eu}^{3+}, \mathrm{Dy}^{3+}, \mathrm{Er}^{3+}, \mathrm{Yb}^{3+} \\
\text { Ambiguous: } \mathrm{Pr}^{3+}, \mathrm{Sm}^{3+}, \mathrm{Ho}^{3+},\end{array}$ \\
\hline REE detection limit & down to $\sim 0.10 \mathrm{wt} . \%$ & less than $0.03 \mathrm{wt} . \%$ \\
\hline Acquisition time: Point measurements & ms-s & ms-s \\
\hline Acquisition time: Mapping of $100 \times 100$ px & $\begin{array}{l}\text { ms-s (commercial push broom and } \\
\text { frame-based sensors available) }\end{array}$ & hours ( $\mathrm{x}-\mathrm{y}$ rastering of point measurements) \\
\hline Quantitative analysis & $\begin{array}{l}\text { semi-quantitative by correlation of } \\
\text { absorption depth and position } \\
\text { with REE grade }\end{array}$ & not yet applicable \\
\hline
\end{tabular}

\subsection{Qualitative REE Detection}

REE can be classified into four groups according to their qualitative detectability by the used PL and reflectance spectroscopy methods in natural samples with mixed REE content (see also Figure 9):

(I) No detectable features for both methods: $\mathrm{Sc}^{3+}, \mathrm{Y}^{3+}, \mathrm{La}^{3+}, \mathrm{Gd}^{3+}, \mathrm{Lu}^{3+}$

(II) Weak, masked or otherwise inconsistently detectable features for both methods: $\mathrm{Tb}^{3+}$, $\mathrm{Ho}^{3+}, \mathrm{Tm}^{3+}$

(III) Well detectable features for one spectroscopic method: $\mathrm{Ce}^{3+}, \mathrm{Pr}^{3+}, \mathrm{Sm}^{3+}, \mathrm{Eu}^{3+}, \mathrm{Er}^{3+}$

(IV) Well detectable features for both spectroscopic methods: $\mathrm{Nd}^{3+}, \mathrm{Dy}^{3+}, \mathrm{Yb}^{3+}$ 


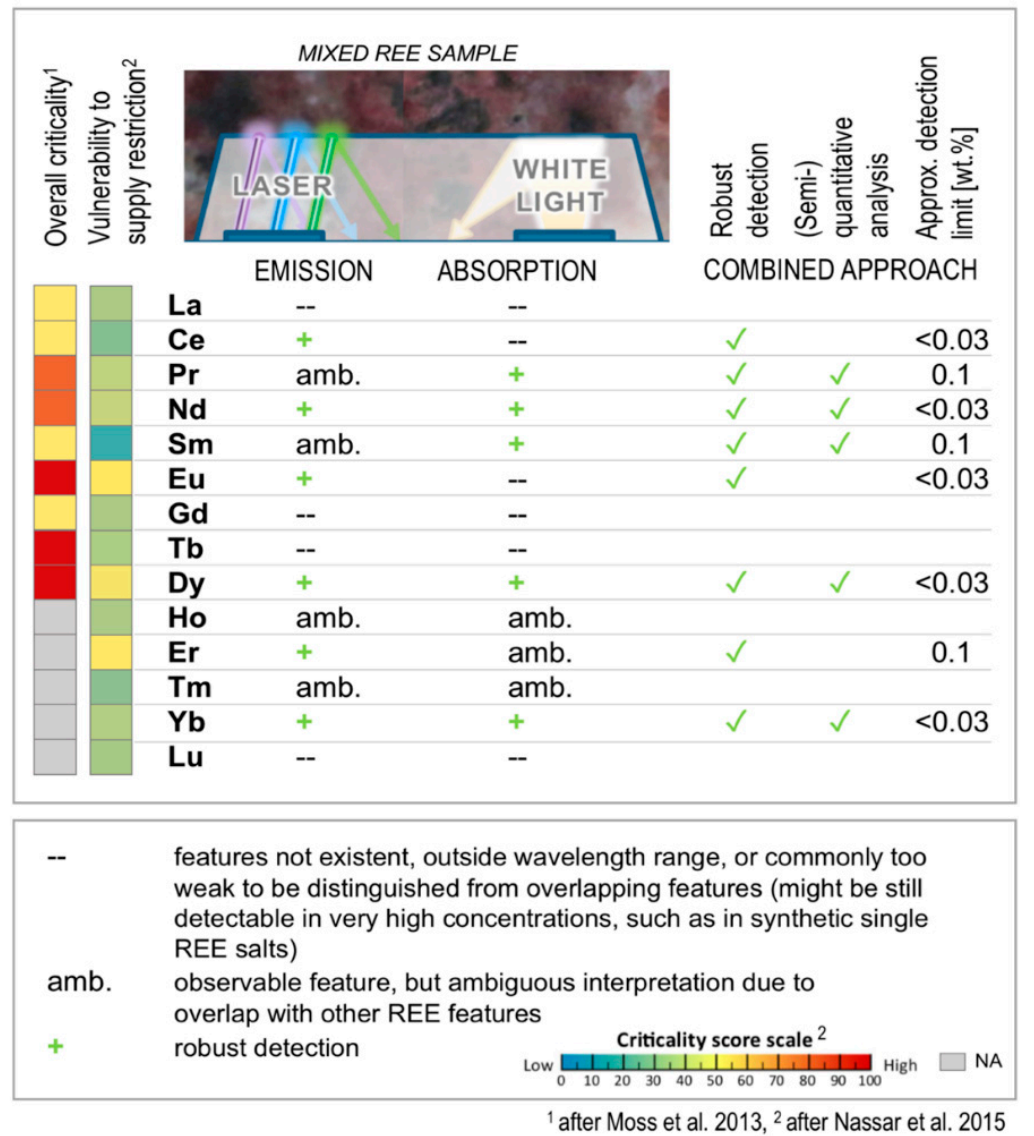

Figure 9. Overview on the performance of the employed reflectance and PL approaches for the detection of REE and the possibilities of a combined approach. A comparison of detectability with criticality and vulnerability to supply restrictions of the individual REE shows the economic value of the presented approach (NA: no data available).

The classification shows that few REE, which were well detectable in single-REE standards [35], feature a decreased or inconsistent detectability in mixed natural samples for either one or both methods. This applies especially for $\mathrm{Pr}^{3+}, \mathrm{Sm}^{3+}, \mathrm{Tb}^{3+}, \mathrm{Ho}^{3+}$ and $\mathrm{Tm}^{3+}$. Two main explanations can be found: (1) hindered detection through overlapping REE- or mineral-matrix-related features (especially in PL data) and (2) non-comparability of single-REE salt concentrations versus fundamentally lower concentrations of certain REE in natural samples that may fall near or below the detection limit of the used method (especially for reflectance spectroscopy). For example, the concentration of $\mathrm{TbPO}_{4}$ samples used as reference amounts for roughly $60 \mathrm{wt} . \% \mathrm{~Tb}^{3+}$, while in the analysed natural minerals $\mathrm{Tb}^{3+}$ rarely exceeds $1 \mathrm{wt} . \%$ [19]. Thus, REE features showing only weak spectral representations in high-grade single-REE salts might be expected to vanish in natural mixed-REE sample spectra. For the affected elements, a direct detection using one method is often not possible, thus, a combination of both methods and/or a variation in the acquisition parameters such as laser excitation wavelength is needed. For example, $\mathrm{Pr}^{3+}$, as one of the critical REE, is hardly detectable in natural minerals by continuous-wave PL, as its features can be easily confused with the characteristic peaks of $\mathrm{Dy}^{3+}$ at $470-490 \mathrm{~nm}, \mathrm{Sm}^{3+}$ at $600-650 \mathrm{~nm}$ and $\mathrm{Nd}^{3+}$ at $870-900 \mathrm{~nm}$, respectively. By variation of the excitation wavelength, $\mathrm{Dy}^{3+}$ and $\mathrm{Pr}^{3+}$ can be distinguished, as $\mathrm{Dy}^{3+}$ is well observable under $325 \mathrm{~nm}$ but not $442 \mathrm{~nm}$ excitation, which is vice versa for $\mathrm{Pr}^{3+}$. Similar dependencies exist for $\mathrm{Nd}^{3+}$ and $\mathrm{Sm}^{3+}$. With a parallel sample analysis using reflectance spectroscopy, the occurrence and relative content of $\mathrm{Dy}^{3+}$, $\mathrm{Sm}^{3+}$ and $\mathrm{Nd}^{3+}$ can be cross-validated, as those elements show very specific features in reflectance spectroscopy data. By that, the results of reflectance spectroscopy can support the interpretation of PL spectroscopy data. 


\subsection{Quantitative REE Detection and Detection Limits}

In the current study, moderate detection limits of about 0.1 wt. $\% \mathrm{REE}_{2} \mathrm{O}_{3}$ for each spectrally active REE were estimated for reflectance spectroscopy. As shown in Reference [19], the absorption feature depth analysis of similar absorptions at different samples allows for a semi-quantification of the REE content. A relationship between absorption depth and concentration exists and can be used for single defined absorption features. Within this study, we could add on to this by providing a semi-quantification approach for overlapping REE features using the minimum wavelength position. The respective analysis of the best observable REE absorption feature at $800-810 \mathrm{~nm}$ enables a straight-forward sample categorization into HREE (low $\mathrm{Nd}^{3+}-/ \mathrm{Dy}^{3+}$ ratio, feature shifted to longer wavelengths) or LREE (high $\mathrm{Nd}^{3+}-/ \mathrm{Dy}^{3+}$ ratio, feature shifted to shorter wavelengths) enriched mineralization. Equivalent analyses could be used to evaluate the $\mathrm{Nd}^{3+} / \mathrm{Pr}^{3+}-(580-595 \mathrm{~nm})$, $\mathrm{Er}^{3+} / \mathrm{Ho}^{3+}-(540-545 \mathrm{~nm})$ and $\mathrm{Tm}^{3+} / \mathrm{Dy}^{3+}$-ratios $(760-780 \mathrm{~nm})$ of different samples.

In contrast, PL spectroscopy provides significantly lower detection limits but currently without the possibility of robust quantification. In many samples, distinct emissions could be unequivocally attributed to REE that were not or only in very low amounts detected by EMPA. As the EMPA detection limit for each REE was in average given with $0.03 \mathrm{wt} . \% \mathrm{REE}_{2} \mathrm{O}_{3}$, a similar or even lower detection limit for PL spectroscopy can be assumed. However, the relation between emission intensity and REE content was inconsistent, up to the point of no or extremely weak detection despite EMPA proven REE occurrence. This confirms the findings of Friis [11] and Lenz [30], stating the complexity of REE emission and the resulting difficulty of REE quantification using PL analysis.

\subsection{Considerations on the Measurement Setup}

\subsubsection{Spatial Data Integration}

A successful integration of PL and reflectance spectroscopy results is dependent on the subsequent observation of the exact same spot of the sample. This applies not only between reflectance and PL spectroscopy results but also between PL measurements with different excitation wavelengths. Hereby, not only the lateral extent and position correspondence of the measurement spot needs to be considered. At constant excitation wavelength, the penetration depth of a certain light source is also dependent on the optical and chemical characteristics of the investigated sample type [11]. In addition to that, a relation between the wavelength of the illumination source and penetration depth exists. Such, a $532 \mathrm{~nm}$ laser reaches a slightly deeper penetration than a $325 \mathrm{~nm}$ laser with the same power at the same surface spot and therefore also stimulates deeper zones of the mineral crystal or, in case of very small grains or heterogeneous samples, can also excite emissions of surrounding minerals or embedding resin. These usually broad emissions can interfere with the target emission by both signal mixture as well as by providing a broad signal in which absorption effects can occur. These can mask or interfere smaller emission peaks nearby and complicate the overall spectral interpretation (see also Section 4.2.3).

\subsubsection{Excitation Wavelength}

A variation of the laser excitation wavelength can be used to highlight or suppress specific REE emissions and also to minimize the influence of possible mineral matrix background emissions. However, the use of a laser with a longer excitation wavelength also leads generally to a loss in spectral coverage, as only features in a wavelength range longer than the laser excitation wavelength are recorded. Up-conversion measurements that enable the detection of emission features at shorter wavelengths than the laser wavelength could be a work-around and subject of a subsequent study.

\subsubsection{Sample Size and Spatial Resolution}

For both single-REE salts as well as mixed-REE natural mineral grains, the detectability by reflectance spectroscopy was highly influenced by the sample size. Some of the analysed single grains 
samples featured diameters of less than a millimetre and even lower thicknesses. This made them hard to investigate with the portable spectroradiometer, whose measurement spot size exceeds the sample size. Thus, for very small or thin and transparent samples spectral mixing with the embedding resin or the surface below the analysed sample can occur. Additionally, scattering of the emitted and reflected light within the transparent embedding resin can lead to additional disturbances within the observed spectral signal. Such spectral influences from neighbouring or surrounding materials must also be expected for future measurements on rock samples. For this reason, it makes sense to consider the grain size of the examined sample when selecting the sensor parameters for both PL and reflectance measurements.

\subsubsection{Sensor Calibration}

During the measurements, a constant and distinct calibration offset of about $10 \mathrm{~nm}$ between the measured spectral signal and the expected wavelength labelling was observed for the Rikola sensor. As this might be expected also for other sensors, routine calibration checks are highly recommended. By that, instrumental deviations can be distinguished from natural variability in absorption features, which occur due to changes in chemical concentration, spectral mixtures or environmental effects. This is especially important for the analysis of overlapping REE absorption features, which relies on the evaluation of the exact absorption position. The calibration could be easily done by a reference measurement of a standard material with a known absorption feature position.

\section{Conclusions}

Our study outlines the strengths of combining reflectance and PL spectroscopy for the detection of REE in natural minerals. Challenges accompanying the analysis of natural samples using only one of the two methods, such as masking of characteristic features by broad mineral matrix emissions and overlapping REE features, can be addressed by this combined approach. The integration of reflectance spectra and luminescence induced by continuous-wave lasers with different excitation wavelengths offers a possibility to cross-validate the observed results and robustly assign otherwise ambiguous features to specific REE. This increases the certainty of correct feature interpretation and enables more robust detection of economically important REE, including Ce, Pr, Nd, Sm, Eu, Dy, Er, Yb and potentially also Ho and Tm. PL spectroscopy provides an extremely high sensitivity such that it partly outruns the detection limit of the conducted EMPA measurements (here: $\sim 0.03 \mathrm{wt} . \%$ per individual $\left.\mathrm{REE}_{2} \mathrm{O}_{3}\right)$. Reflectance spectroscopy in general delivers a higher detection limit $(>0.10 \mathrm{wt}$ \% for selected $\mathrm{REE}_{2} \mathrm{O}_{3}$ ) but in contrast offers the possibility for semi-quantification through the analysis of absorption depth or, in case of highly overlapping features, absorption position.

The integrated reflectance and PL spectroscopy offers already at the present laboratory stage an innovative, robust tool for non-invasive REE detection in near-field (in the range of 0.5 to $2.0 \mathrm{~m}$ ) raw material exploration. It delivers especially advances in small-scale, high-precision sample mapping and can directly be applied to REE detection in ore samples, drill cores and as fast validation approach in large-scale REE exploration.

As the integrated reflectance and PL analysis has now been proven to be successful for natural and complex samples, the next steps will need to focus on the technical implementation and the optimization of sensor parameters such as spatial and spectral resolution to produce integrable mineral maps. Co-registration of the resulting PL data cubes with the presented HS reflectance imagery will allow a pixel-wise integration and by that, a combined mapping approach uniting the strengths of both methods. Further technical optimization may include the implementation of time-resolved PL as it is known to increase the discriminability of specific REE but this will be at the cost of increasing the complexity of the setup, while already great benefit could be achieved with the integration of the here presented simple PL instrumentation.

The relevance of integrating reflectance and PL spectroscopy for mineral mapping lies at present in a wide range of near field sensing applications with focus on any REE detection, may it be in geology, 
exploration, mining, processing or recycling. Expanding especially the PL spectral library beyond the focus on REE has significant potential to enable the robust detection and cross-validation of other critical raw materials.

Applications beyond the current near-field scale need to tackle especially the challenge of ambient light for PL spectroscopy. Similar questions apply for the simultaneous acquisition of reflectance and PL signals using narrow and broad-band illumination at the same time. Both applications are generally possible but require specific solutions, because PL signals are orders of magnitude less intense and rely on sufficient discrimination from much brighter reflectance signals and ambient light, respectively. Yet, a technical solution is available in form of, for example, a Fluorescence LIDAR system [43] for biogenic materials. To transfer the approach to the essentially weaker REE signal is possible but requires advanced camera systems of high sensitivity and distinctly increased power of the laser excitation source. Besides security issues and possible sample altering, interferences between REE emission and absorption features occurring in close spectral proximity will cause a loss in informative value. For these reasons, the detailed and sensitive REE characterization is the strength of our combined spectroscopic approach. A separate acquisition guarantees to record the full range of information from both methods and is suitable especially for small sample-sensor distances ( $\mathrm{cm}$ to $\mathrm{m}$ ) under separate acquisition of reflectance and PL spectra.

Author Contributions: Conceptualization, S.L., M.F. and R.G.; Formal analysis, S.L., M.F. and P.S.; Investigation, S.L. and J.B.; Resources, J.B. and D.T.; Software, S.L. and M.F.; Supervision, J.H. and R.G.; Validation, S.L.; Visualization, S.L.; Writing—original draft, S.L.; Writing—review \& editing, J.B., M.F., P.S., D.T., J.H. and R.G.

Funding: This research received no external funding.

Acknowledgments: We like to thank Robert Zimmermann (HZDR-HIF) for his engineering support during the HS recordings.

Conflicts of Interest: The authors declare no conflict of interest.

\section{References}

1. European Commission. Communication from the Commission to the European Parliament, the Council, the European Economic and Social Committee and the Committee of the Regions; On the Review of the List of Critical Raw Materials for the EU and the Implementation of the Raw Materials Initiative; European Commission: Brussels, Belgium, 2014.

2. European Commission. Communication from the Commission to the European Parliament, the Council, the European Economic and Social Committee and the Committee of the Regions on the 2017 List of Critical Raw Materials for the $E U ;$ European Commission: Brussels, Belgium, 2017.

3. Bauer, D.; Diamond, D.; Li, J.; Sandalow, D.; Telleen, P.; Wanner, B. Critical Materials Strategy; U.S. Department of Energy: Washington, DC, USA, 2010; p. 166.

4. Moss, R.; Tzimas, E.; Willis, P.; Arendorf, J.; Thompson, P.; Chapman, A.; Morley, N.; Sims, E.; Bryson, R.; Peason, J.; et al. Critical Metals in the Path towards the Decarbonisation of the EU Energy Sector: Assessing Rare Metals as Supply-Chain Bottlenecks in Low-Carbon Energy Technologies; European Commission: Brussels, Belgium, 2013; p. 242.

5. Guyonnet, D.; Planchon, M.; Rollat, A.; Escalon, V.; Tuduri, J.; Charles, N.; Vaxelaire, S.; Dubois, D.; Fargier, H. Material flow analysis applied to rare earth elements in Europe. J. Clean. Prod. 2015, 107, 215-228. [CrossRef]

6. Nassar, N.T.; Du, X.; Graedel, T.E. Criticality of the Rare Earth Elements. J. Ind. Ecol. 2015, 19, $1044-1054$. [CrossRef]

7. Rajendran, S.; Nasir, S.; Kusky, T.M.; Ghulam, A.; Gabr, S.; El-Ghali, M.A.K. Detection of hydrothermal mineralized zones associated with listwaenites in Central Oman using ASTER data. Ore Geol. Rev. 2013, 53, 470-488. [CrossRef]

8. Zimmermann, R.; Brandmeier, M.; Andreani, L.; Mhopjeni, K.; Gloaguen, R. Remote Sensing Exploration of $\mathrm{Nb}$-Ta-LREE-Enriched Carbonatite (Epembe/Namibia). Remote Sens. 2016, 8, 620. [CrossRef]

9. Shavers, E.J.; Ghulam, A.; Encarnacion, J. Surface alteration of a melilitite-clan carbonatite and the potential for remote carbonatite detection. Ore Geol. Rev. 2018, 92, 19-28. [CrossRef] 
10. Turner, D.; Rivard, B.; Groat, L.A. Visible to shortwave infrared reflectance spectroscopy of rare earth element minerals. In British Columbia Geological Survey Paper; Simandl, G.J., Neetz, M., Eds.; British Columbia Ministry of Energy and Mines: Victoria, BC, USA, 2015; Volume 3, pp. 219-229.

11. Friis, H. Luminescence Spectroscopy of Natural and Synthetic REE-bearing Minerals. Ph.D. Thesis, University of St. Andrews, St. Andrews, UK, 2009.

12. Adams, J.W. The visible region absorption spectra of rare earth minerals. Am. Mineral. 1965, 50, 356-366.

13. Dieke, G.H.; Crosswhite, H.M. The Spectra of the Doubly and Triply Ionized Rare Earths. Appl. Opt. 1963, 2, 675-686. [CrossRef]

14. Jassie, L.B. Diffuse reflectance spectra of ten rare earths. Spectrochim. Acta 1964, 20, 169-177. [CrossRef]

15. White, W.B. Diffuse-Reflectance Spectra of Rare-Earth Oxides. Appl. Spectrosc. 1967, 21, 167-171. [CrossRef]

16. Ropp, R.C. Phosphors Based on Rare Earth Phosphates: II. Reflection Spectra of Rare Earth Phosphates. J. Electrochem. Soc. 1969, 116, 623-629. [CrossRef]

17. Weidner, V.R.; Barnes, P.Y.; Eckerle, K.L. A wavelength standard for the near infrared based on the reflectance of rare-earth oxides. J. Res. Natl. Bur. Stand. 1986, 91, 243. [CrossRef]

18. Rowan, L.C.; Kingston, M.J.; Crowley, J.K. Spectral reflectance of carbonatites and related alkalic igneous rocks; selected samples from four North American localities. Econ. Geol. 1986, 81, 857-871. [CrossRef]

19. Turner, D. Reflectance spectroscopy and imaging spectroscopy of rare earth element-bearing mineral and rock samples. Ph.D. Thesis, University of British Columbia, Vancouver, BC, USA, 2015.

20. Turner, D.J.; Rivard, B.; Groat, L.A. Visible and short-wave infrared reflectance spectroscopy of REE fluorocarbonates. Am. Mineral. 2014, 99, 1335-1346. [CrossRef]

21. Turner, D.J.; Rivard, B.; Groat, L.A. Visible and short-wave infrared reflectance spectroscopy of selected REE-bearing silicate minerals. Am. Mineral. 2018, 103, 927-943. [CrossRef]

22. Huntington, J.; Laukamp, C. Drill Core Reflectance Spectroscopy applied to the Carbonatite hosted REE deposit at Cummins Range (Australia). In Proceedings of the 13th SGA Biennal Meeting, Nancy, France, 24-27 August 2015; Volume 3, pp. 1017-1020.

23. Turner, D.; Rivard, B.; Groat, L. Rare earth element ore grade estimation of mineralized drill core from hyperspectral imaging spectroscopy. In Proceedings of the 2014 IEEE Geoscience and Remote Sensing Symposium, Quebec City, QC, Canada, 13-18 July 2014; IEEE: Quebec City, QC, Canada, 2014; pp. 4612-4615.

24. Bösche, N.K.; Rogaß, C.; Mielke, C.; Kaufmann, H. Hyperspectral digital image analysis and geochemical analysis of a rare earth elements mineralized intrusive complex (fen carbonatite complex in Telemarkregion, Norway). In Proceedings of the EARSeL 34th Symposium, Warsaw, Poland, 16-20 June 2014; Volume 13, pp. 1-6.

25. Rowan, L.C.; Mars, J.C. Lithologic mapping in the Mountain Pass, California area using Advanced Spaceborne Thermal Emission and Reflection Radiometer (ASTER) data. Remote Sens. Environ. 2003, 84, 350-366. [CrossRef]

26. Neave, D.A.; Black, M.; Riley, T.R.; Gibson, S.A.; Ferrier, G.; Wall, F.; Broom-Fendley, S. On the Feasibility of Imaging Carbonatite-Hosted Rare Earth Element Deposits Using Remote Sensing. Econ. Geol. 2016, 111, 641-665. [CrossRef]

27. McDowell, M.L.; Kruse, F.A. Integrated visible to near infrared, short wave infrared and long wave infrared spectral analysis for surface composition mapping near Mountain Pass, California. In Proceedings of the Algorithms and Technologies for Multispectral and Ultraspectral Imagery XXI, Baltimore, MD, USA, 20-24 April 2015; Velez-Reyes, M., Kruse, F.A., Eds.; p. 94721C.

28. Booysen, R.; Zimmermann, R.; Lorenz, S.; Gloaguen, R.; Nex, P.A.M. Multi-source hyperspectral imaging of carbonatite-hosted REE-Nb- Ta mineralization at Marinkas Quellen, Namibia. In Proceedings of the 9th IEEE Whispers Conference-Hyperspectral Image and Signal Processing Workshop, Amsterdam, The Netherlands, 23-26 September 2018.

29. Lüthi, B. Crystal field effects in rare earth systems. J. Magn. Magn. Mater. 1980, 15-18, 1-8. [CrossRef]

30. Lenz, C.; Talla, D.; Ruschel, K.; Škoda, R.; Götze, J.; Nasdala, L. Factors affecting the Nd3+ (REE3+) luminescence of minerals. Mineral. Petrol. 2013, 107, 415-428. [CrossRef]

31. Gaft, M.; Shoval, S.; Panczer, G.; Nathan, Y.; Champagnon, B.; Garapon, C. Luminescence of uranium and rare-earth elements in apatite of fossil fish teeth. Palaeogeogr. Palaeoclimatol. Palaeoecol. 1996, 126, 187-193. [CrossRef] 
32. Gaft, M.; Reisfeld, R.; Panczer, G.; Blank, P.; Boulon, G. Laser-induced time-resolved luminescence of minerals. Spectrochim. Acta A Mol. Biomol. Spectrosc. 1998, 54, 2163-2175. [CrossRef]

33. Gaft, M.; Reisfeld, R.; Panczer, G.; Uspensky, E.; Varrel, B.; Boulon, G. Luminescence of Pr3+ in minerals. Opt. Mater. 1999, 13, 71-79. [CrossRef]

34. Gaft, M.; Reisfeld, R.; Panczer, G. Modern Luminescence Spectroscopy of Minerals and Materials; Springer: Berlin, Germany; New York, NY, USA, 2005; ISBN 978-3-540-21918-7.

35. Fuchs, M.C.; Gloaguen, R.; Beyer, J.; Jakob, S.; Heitman, J. Emission spectroscopy for the identification of rare earth elements using laser-induced photoluminescence. In Proceedings of the 2016 8th Workshop on Hyperspectral Image and Signal Processing: Evolution in Remote Sensing (WHISPERS), Los Angeles, CA, USA, 21-24 August 2016; pp. 1-5.

36. Lenz, C.; Nasdala, L.; Talla, D.; Hauzenberger, C.; Seitz, R.; Kolitsch, U. Laser-induced REE3+ photoluminescence of selected accessory minerals-An "advantageous artefact" in Raman spectroscopy. Chem. Geol. 2015, 415, 1-16. [CrossRef]

37. Keizer, P.D.; Gordon, D.C., Jr. Detection of Trace Amounts of Oil in Sea Water by Fluorescence Spectroscopy. J. Fish. Res. Board Can. 1973, 30, 1039-1046. [CrossRef]

38. Kim, H.H. New Algae Mapping Technique by the Use of an Airborne Laser Fluorosensor. Appl. Opt. 1973, 12, 1454-1459. [CrossRef] [PubMed]

39. Rogers, S.R.; Webster, T.; Livingstone, W.; O’Driscoll, N.J. Airborne Laser-Induced Fluorescence (LIF) Light Detection and Ranging (LiDAR) for the Quantification of Dissolved Organic Matter Concentration in Natural Waters. Estuar. Coasts 2012, 35, 959-975. [CrossRef]

40. Saito, Y.; Ichihara, K.; Morishita, K.; Uchiyama, K.; Kobayashi, F.; Tomida, T. Remote Detection of the Fluorescence Spectrum of Natural Pollens Floating in the Atmosphere Using a Laser-Induced-Fluorescence Spectrum (LIFS) Lidar. Remote Sens. 2018, 10, 1533. [CrossRef]

41. Günther, K.P.; Dahn, H.-G.; Lüdeker, W. Remote sensing vegetation status by laser-induced fluorescence. Remote Sens. Environ. 1994, 47, 10-17. [CrossRef]

42. Hoge, F.E.; Swift, R.N.; Yungel, J.K. Feasibility of airborne detection of laser-induced fluorescence emissions from green terrestrial plants. Appl. Opt. 1983, 22, 2991-3000. [CrossRef]

43. Raimondi, V.; Cecchi, G.; Lognoli, D.; Palombi, L.; Grönlund, R.; Johansson, A.; Svanberg, S.; Barup, K.; Hällström, J. The fluorescence lidar technique for the remote sensing of photoautotrophic biodeteriogens in the outdoor cultural heritage: A decade of in situ experiments. Int. Biodeterior. Biodegrad. 2009, 63, 823-835. [CrossRef]

44. Forget, S.; Chénais, S. Organic Solid-State Lasers; Springer Series in Optical Sciences; Springer: Berlin/Heidelberg, Germany, 2013.

45. Nienhaus, K.; Bayer, A.K. Innovative Systems for Horizon Control of Mining Machines by Means of Laser Induced Fluorescence (LIF). In Proceedings of the International Symposium on Mine Planning and Equipment Selection, Kalgoorlie, WA, Australia, 23-25 April 2003; pp. 1-7.

46. Broicher, H.F. Dilution control-Online and real-time recognition of ore and waste by LIF. In Proceedings of the SME Annual Meeting, Salt Lake City, UT, USA, 28 February-02 March 2005; Volume 05-66, pp. 1-5.

47. Pollmanns, J. Identifikation von Mineralien und Schüttgütern mit Hilfe der laserinduzierten Fluoreszenz. Bergbau 2008, 7, 322-325.

48. Baumann, N.; Arnold, T.; Foerstendorf, H.; Read, D. Spectroscopic Verification of the Mineralogy of an Ultrathin Mineral Film on Depleted Uranium. Environ. Sci. Technol. 2008, 42, 8266-8269. [CrossRef] [PubMed]

49. Kauppinen, T.; Khajehzadeh, N.; Haavisto, O. Laser-induced fluorescence images and Raman spectroscopy studies on rapid scanning of rock drillcore samples. Int. J. Miner. Process. 2014, 132, 26-33. [CrossRef]

50. Green, A.A.; Berman, M.; Switzer, P.; Craig, M.D. A transformation for ordering multispectral data in terms of image quality with implications for noise removal. IEEE Trans. Geosci. Remote Sens. 1988, 26, 65-74. [CrossRef]

51. Bakker, W.H.; van Ruitenbeek, F.J.A.; van der Werff, H.M.A. Hyperspectral image mapping by automatic color coding of absorption features. In Proceedings of the 7th EARSEL Workshop of the Special Interest Group in Imaging Spectroscopy, Edinburgh, UK, 11-13 April 2011; pp. 56-57. 
52. Murphy, R.J.; Schneider, S.; Monteiro, S.T. Consistency of measurements of wavelength position from hyperspectral imagery: Use of the ferric iron crystal field absorption at $\sim 900 \mathrm{~nm}$ as an indicator of mineralogy. IEEE Trans. Geosci. Remote Sens. 2014, 52, 2843-2857. [CrossRef]

53. Reisfeld, R.; Gaft, M.; Boulon, G.; Panczer, C.; Jørgensen, C.K. Laser-induced luminescence of rare-earth elements in natural fluor-apatites. J. Lumin. 1996, 69, 343-353. [CrossRef]

54. Kim, S.; Rhee, S.J.; Li, X.; Coleman, J.J.; Bishop, S.G. Photoluminescence and photoluminescence excitation spectroscopy of multiple Nd 3 + sites in Nd-implanted GaN. Phys. Rev. B 1998, 57, 14588-14591. [CrossRef]

55. Rastsvetaeva, R.K. Structural mineralogy of the eudialyte group: A review. Crystallogr. Rep. 2007, 52, 47-64. [CrossRef]

56. Gaft, M. Application of thermal treatment of zircon for the interpretation of luminescence centers. J. Therm. Anal. 1992, 38, 2281-2290. [CrossRef]

57. Gaft, M. Laser-Induced Time-Resolved Luminescence and Laser-Induced Breakdown Spectroscopy for Evaluation of Phosphates with High Dolomite Content. In Benefication of Phosphates, Fundamentals and Technology; SME: Littleton, CO, USA, 2002; pp. 145-152.

58. Burns, R.G. Mineralogical Applications of Crystal Field Theory; Cambridge Topics in Mineral Physics and Chemistry; Cambridge University Press: Cambridge, UK, 1993.

(C) 2018 by the authors. Licensee MDPI, Basel, Switzerland. This article is an open access article distributed under the terms and conditions of the Creative Commons Attribution (CC BY) license (http://creativecommons.org/licenses/by/4.0/). 